\title{
Venom-derived modulators of epilepsy-related ion channels
}

Chun Yuen Chow ${ }^{\mathrm{a}}$, Nathan Absalom ${ }^{\mathrm{b}}$, Kimberley Biggs ${ }^{\mathrm{a}}$, Glenn F. King ${ }^{\mathrm{a} *}$ and Linlin Mac*

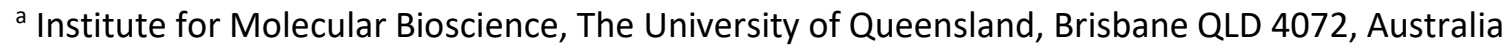

${ }^{b}$ Brain and Mind Centre, School of Pharmacy, Faculty of Health and Medicine, The University of Sydney, Sydney, NSW 2050, Australia

c Griffith Institute for Drug Discovery, Griffith University, Nathan, QLD 4111, Australia

\section{*Address for correspondence}

Prof. Glenn F. King, Institute for Molecular Bioscience, The University of Queensland, 306 Carmody Road, St. Lucia, QLD 4072, Australia Email: glenn.king@imb.uq.edu.au; Phone: +61 7 3346-2025.

Dr. Linlin Ma, Griffith Institute for Drug Discovery, Griffith University, Nathan, QLD 4111, Australia Email: Linlin.ma@griffith.edu.au; Phone: +61 7 3735-4175

Keywords: epilepsy, ion channel, venom peptide, Cys-loop receptor, ionotropic glutamate receptor, P2X receptor 


\section{ABSTRACT}

Epilepsy is characterised by spontaneous recurrent seizures that are caused by an imbalance between neuronal excitability and inhibition. Since ion channels play fundamental roles in the generation and propagation of action potentials as well as neurotransmitter release at a subset of excitatory and inhibitory synapses, their dysfunction has been linked to a wide variety of epilepsies. Indeed, these unique proteins are the major biological targets for antiepileptic drugs. Selective targeting of a specific ion channel subtype remains challenging for small molecules, due to the high level of homology among members of the same channel family. As a consequence, there is a growing trend to target ion channels with biologics. Venoms are the best known natural source of ion channel modulators, and venom peptides are increasingly recognised as potential therapeutics due to their high selectivity and potency gained through millions of years of evolutionary selection pressure. Here we describe the major ion channel families involved in the pathogenesis of various types of epilepsy, including voltage-gated $\mathrm{Na}^{+}$, $\mathrm{K}^{+}, \mathrm{Ca}^{2+}$ channels, Cys-loop receptors, ionototropic glutamate receptors and P2X receptors, and currently available venom-derived peptides that target these channel proteins. Although only a small number of venom peptides have successfully progressed to the clinic, there is reason to be optimistic about their development as anti-epileptic drugs, notwithstanding the challenges associated with development of any class of peptide drug. 


\section{Introduction}

Epilepsy, which is characterised by recurrent seizures due to uncontrolled electrical discharge of cerebral neurons, is one of the most prevalent neurological disorders [1]. Some epilepsies are triggered by congenital malformations or physical traumas such as brain injury, stroke, infections, or brain tumour, and $30-40 \%$ have a genetic origin; however, in $~ 50 \%$ of cases the underlying cause of the epilepsy is unknown [1]. The impact of a seizure differs significantly from person to person, as do the clinical manifestations which can include prolonged loss of consciousness, and motor, sensory, autonomic or psychic symptoms [2]. More than 65 million people worldwide have epilepsy [3], of which about one-third suffer from ongoing, refractory epilepsy that cannot be controlled with currently available antiepileptic drugs (AEDs) [4]. Even those patients whose seizures can be controlled with AEDs often suffer from side-effects such as sedation, dizziness, somnolence, and ataxia. Moreover, sudden unexpected death in epilepsy (SUDEP) is seen not only in patients with uncontrolled chronic epilepsy, but also in seemingly well-controlled patients during a seizure [5]. Therefore, there is a critical unmet need for more effective and safer therapies for epilepsy patients, particularly those with comorbidities such as depression, anxiety, migraine, and cognitive impairment [4].

The pathogenesis of epilepsy is highly complex, as it can result from primary genetic abnormalities or secondary to other structural or metabolic disorders. A recent study summarised 977 epilepsy associated genes, among which ion channel-encoding genes predominate [6]. Ion channels are fundamental not only for generating and modulating neuronal excitability, but also for maintaining cellular ion homoeostasis and membrane potential, and consequently they are critical for many cellular activities, such as neurotransmitter release, muscle contraction, signal transduction, hormone secretion, volume regulation, growth, and motility [7]. More than 300 ion channels have been identified in humans. Gain-of-function (GOF) or loss-of-function (LOF) mutations in ion channel genes have been reported to cause diverse epilepsy phenotypes with distinct mechanisms [8]. Ion channel modifiers are therefore highly desirable drug candidates for treating different types of epilepsies. 
Animal venoms, in particular those produced by venomous invertebrates, are a rich resource of highly potent and specific ion channel modifiers, because targeting ion channels is the most efficient way for venomous animals to rapidly immobilise prey or deter predators [9]. Invertebrate venoms are complex chemical cocktails that are rich in disulfide-rich peptides. These peptides typically have high thermal and chemical stability as well as resistance to proteases [10], and therefore they have become valuable as pharmacological tools [11], bioinsecticides $[12,13]$, and therapeutics $[9,14,15]$. For example, the FDA-approved analgesic drug ziconotide (trade name Prialt ${ }^{\circledR}$ ), is a disulfide-rich peptide from venom of the marine cone snail Conus magus that inhibits a specific subtype of voltage-gated calcium (Cav) channel. It has been successfully used to treat severe chronic pain in patients that are intolerant or refractory to systemic analgesics or intrathecal morphine [16]. Venom peptides from various species are currently under investigation for the treatment of an extremely diverse range of pathologies (e.g. [17-20]), including epilepsy [21-23]. This review will focus on the pathogenic roles of epilepsyassociated ion channels and progress in using venom peptides to develop both tools and precision therapeutics for epilepsy.

\section{Epilepsy as a channelopathy}

According to the World Health Organisation, epilepsy accounts for $1 \%$ of the global disease burden with an estimated prevalence of 4-10 per 1,000 population [24]. The life expectancy of patients with epilepsy is $2-3$ times lower than that of the general population, and increased mortality is an issue for all epilepsy patients $[5,25]$. Causes of death can be broadly divided into three groups: unrelated to epilepsy (e.g. respiratory infections and cardiovascular disease outside the nervous system) [26]; the underlying neurological disorders related to pathology in symptomatic epilepsy (e.g., stroke and brain tumour) $[27,28]$; and direct epilepsy-related causes such as suicide, seizure-related accidents, status epilepticus (SE), and SUDEP [29-31]. In children and adolescents, epilepsy is often attributed to birth trauma, congenital abnormalities or genetic disorders. In middle-aged adults and the elderly, the onset is predominantly due to strokes, tumours and cerebrovascular diseases. The detailed underlying 
mechanism of epilepsy development is unknown in more than half of all epilepsy cases, but the current available knowledge of the central nervous system (CNS) sets a solid foundation for our exploration of the pathophysiology of epilepsy.

\subsection{Pathophysiology of epilepsy}

The cerebral cortex comprises two broad classes of neurons: principal neurons and interneurons. Principal neurons such as pyramidal neurons are mainly excitatory neurons that transmit information to distant neurons, whereas interneurons (e.g., basket cells) are integral for local inhibition via formation of inhibitory feedback circuits. Neurons communicate via a combination of electrical and chemical processes through action potentials and neurotransmitters respectively [32]. Action potentials arise from membrane depolarisation and encode information in their frequencies and patterns in neuronal cell bodies. They then rapidly propagate down the axon to induce neurotransmitter release at the axon terminal. These processes are mediated by a diverse range of ion channels [7]. Voltage-gated ion channels are responsible for axonal conduction within a neuron, whereas ligand-gated ion channels are involved in synaptic transmission between neighbouring cells. In the mammalian cortex, glutamate and $\gamma$-aminobutyric acid (GABA) are the most abundant excitatory and inhibitory neurotransmitters, respectively. Due to their ability to exert either excitatory or inhibitory effects on postsynaptic neurons, these neurotransmitters play a major modulatory role in brain excitability and, consequently, in epilepsy [33].

The normal neuronal activity in the brain relies on a finely tuned balance between ongoing excitatory and inhibitory inputs regulated by ion channels. Seizures can be conceptualised as occurring when there is over-excitation or reduced inhibition, leading to uncontrolled hyperexcitability of individual neurons and hypersynchronous firing of neuronal networks; however, this is an oversimplification. There are numerous seizure types and epilepsy syndromes associated with an abnormal increase in inhibition [34, 35]. In addition, inhibitory synaptic function occurs later in development, as at an early developmental stage GABA causes excitation of neurons [36], and during the second postnatal week, 
the balance between excitation and inhibition is established [37]. This may explain why the developing cerebral cortex is highly susceptible to s. The imbalance between excitation and inhibition can result from an alternation at many levels of brain function, from genes and subcellular signalling cascades to the whole neuronal network [38]. For focal onset seizures, epileptogenic networks are distributed in only one half of the cerebrum and were thought to arise by an acquired or congenital structural lesion including stroke, trauma, tumour and brain infection [39]. By contrast, generalised onset seizures originate within bilaterally distributed networks, and are thought to be driven by genetic abnormalities [40]. These networks can include cortical and subcortical structures and do not necessarily involve the whole cortex [41].

\subsection{Ion channels involved in epilepsy}

A genetic basis has long been recognised as a major underlying cause of epilepsy. In 1995, CHRNA4, which encodes the $\alpha 4$ subunit of the nicotinic acetylcholine receptor (nAChR), was the first gene identified as an underlying cause of epilepsy in a family with autosomal dominant nocturnal frontallobe epilepsy (ADNFLE) [42]. Since then, many studies have begun to unravel the genetic contribution to epilepsy. Many early pathogenic gene discoveries were made in families with Mendelian inheritance; however, in some cases, epilepsy occurs sporadically without any family history due to de novo somatic mutations $[43,44]$. Somatic mutations, which arise in somatic cells and are not inherited, can occur at any time after fertilisation to cause epilepsy or other neurological diseases [45]. With the advent of molecular genetics and bioinformatic tools, the detection of causative mutations or genes in epilepsy patients has led to early and accurate diagnosis as well as etiology-specific treatment of various epilepsies. Genes encoding ion channel subunits predominate in the pathogenic genes detected [6]. Many of the ion channels implicated in genetic epilepsies are localised to different neuronal subtypes and intracellular compartments (Figure 1). Table 1 summarises the ion channel genes linked to various epilepsy syndromes along with the proposed molecular and cellular deficits. However, it is important to note that a genetic defect does not solely define the cause of epilepsy, as the environmental influences cannot be excluded. 
The involvement of ion channels in genetic epilepsy has been extensively studied in vitro and in vivo. Heterologous expression in non-neuronal models (e.g., Xenopus oocytes or mammalian cell lines) combined with electrophysiological recordings is commonly used to examine the biophysical and molecular properties of mutated ion channels associated with epilepsy [46]. This approach can reveal why the genetic variant causes seizures compared to the wild-type channel. However, a disadvantage of this approach is that mutant channels may behave differently when expressed in non-native cellular environments, and no information is obtained at the level of neuronal networks. In order to understand the effects of mutations on intrinsic neuronal properties, they can be expressed in rodent primary cultures [47] or neuronal cultures derived from induced pluripotent stem cells (iPSCs) obtained from patients [48]. In addition, more sophisticated animal models (e.g., Drosophila, zebrafish, and rodents) not only provide an experimental platform for understanding epileptogenic mechanisms that are more predictive of human brain processes, but allow testing of new therapeutic approaches [49, 50]. If a single causative gene defect gives rise to a common functional change, this might help devise suitable gene-specific therapeutics; however, this is not always the case. There is considerable genetic heterogeneity for some inherited epilepsies, in which mutations of multiple genes within either individuals or between different individuals lead to the same syndrome $[46,51]$. For example, familial syndrome generalised epilepsy with febrile seizures plus (GEFS+) is usually inherited in an autosomal dominant manner with incomplete penetrance, and is associated with mutations in various genes including SCN1A ( $\alpha$ subunit of the voltage-gated sodium channel Nav1.1), SCN1B (Nav channel $\beta 1$ subunit), and GABRG2 ( $\gamma 2$ subunit of $G A B A_{A}$ receptor) [52-54]. This genetic variation in patients poses a major challenge for understanding the precise mechanisms that underlie epileptogenesis.

Adding to this complexity, the correlation between the genotype and phenotype of inherited epilepsies is often opaque, with mutations that have opposing effects on ion channels sometimes leading to disorders with similar or overlapping clinical features. For example, both GOF and LOF mutations in SCN2A, the gene encodes the pore-forming $\alpha$-subunit of Nav1.2, have been identified in patients with self-limited familial neonatal-infantile epilepsy (formerly called benign familial neonatal-infantile 
epilepsy) $[55,56]$. Similarly, both GOF and LOF mutations in KCNQ2, the gene encoding the voltagegated potassium (Kv) channel Kv7.2, can lead to KCNQ2 epilepsy [57].

\subsection{Current pharmaceutical treatment of epilepsy}

AEDs are the first line of treatment for epilepsy. They are often effective in decreasing the frequency of seizures, but side effects are common $[58,59]$. Mechanisms of AED action are beyond the scope of this review and have been covered extensively elsewhere [60]. However, most AEDs reduce the excitability of individual neurons by enhancing GABA-mediated inhibitory neurotransmission, inhibiting glutamate-mediated excitatory neurotransmission, or modulating $\mathrm{Na}_{v}$ channels or $\mathrm{Ca}_{\mathrm{v}}$ channels (Table 2). The type of AED prescribed depends on the patient's age, type of epilepsy, cost, medical history, comorbidities and overall health [61]. In particular, elderly patients are vulnerable to adverse drug reactions due to age-related changes in pharmacodynamics and pharmacokinetics, frailty, and increased risk of comorbidity [62].

Despite the availability of AEDs, about one-third of patients suffer from intractable, drug-resistant seizures $[63,64]$. For example, Dravet syndrome (DS) is an epileptic encephalopathy characterised by childhood-onset polymorphic seizures, multiple neuropsychiatric comorbidities, and a high mortality rate $[65,66]$. More than 30 years after its discovery, there is still no standard treatment DS. The only two FDA-approved drugs for DS, cannabidiol (CBD) and stiripentol (STP), both cause dose-limiting side effects. More than $90 \%$ of patients treated with CBD experience side effects such as fatigue, diarrhea and upper respiratory tract infection, while STP is associated with anorexia and weight loss [67]. Thus, these drugs are limited to symptomatic management of epileptic seizures, and there is an urgent need to develop disease-specific therapies with minimal side effects.

\section{Venom peptides as therapeutics}

Throughout history, humanity has turned to natural products as a source of medicinal treatments. Poisonous and venomous animals are no exception, and they have been used for millennia for treating various ailments. For example, toad secretions have been used in traditional Chinese medicine 
for $>1,000$ years, while tarantulas have been used in the traditional medicine of indigenous populations in Central and South America to treat conditions ranging from cancer to asthma [9]. However, it was not the last half of the 20th century that scientists began to isolate individual components from animal venoms and examine their potential as therapeutics.

The most studied animal venoms to date are those from snakes, marine cone snails, scorpions, and spiders. Snake and lizard venoms have only moderate biochemical complexity, and, although there are exceptions, they tend to target the neuromuscular and cardiovascular systems of their prey [68]. Moreover, the primary components of reptile venoms are large peptides and proteins, and thus these venoms are not an ideal source of ion channel modulators with therapeutic potential. In contrast, the venoms of invertebrate predators such as ants, assassin bugs, centipedes, cone snails, scorpions and spiders target the nervous system of their prey and they are replete with disulfide-rich peptides that have evolved to target neuronal ion channels and receptors with exceptional potency and selectivity [69-74]. Hence these venoms have proven to be a rich source of ion channel modulators with potential for development as pharmacological tools and as therapeutics for treating a wide range of neurological disorders, including epilepsy [75-79].

\subsection{Why venom peptides?}

Peptides are the dominant components of most invertebrate venoms. This is because venomous animals have evolved utilising a genetic strategy that enables massive duplication and diversification of a small number of ancestral toxin genes in order to produce a combinatorial library of bioactive peptides [80-82]. Although the vast majority of venom components remain pharmacologically uncharacterized, the increasing availability of proteomic and transcriptomic analyses, high-throughput screening platforms, efficient methods for chemical and recombinant production of venom peptides, and advanced nuclear magnetic resonance (NMR) spectroscopy techniques, has facilitated the discovery of venom peptides with novel pharmacology and therapeutic potential [83].

The use of peptides as drugs presents major challenges such as poor membrane permeability and oral 
bioavailability. However, they have numerous advantages over small molecules, including high specificity and potency for their targets, lack of tissue accumulation, minimal drug-drug interactions, and efficient metabolism $[84,85]$. Also, challenges in peptide manufacture are being overcome by progress in chemical synthesis and recombinant production methods [86-90]. This may explain in part why biologics have a higher success rate than small molecules for progression from Phase I clinical trials to FDA approval [91]. Six venom-derived peptides and proteins have been approved by the FDA as therapeutics, while many more biologics from animal venoms are currently in clinical trials or in preclinical development $[9,15]$.

\subsection{Spider venom: a remarkable example illustrating a rich source of ion channel modulators}

Spiders, which evolved in the late Ordovician $\sim 450$ million years ago [92], are the most successful venomous animal with more than 48,400 extant species [93]. Spider venom is a highly complex cocktail comprising a heterogeneous mixture of peptides, proteins, small organic molecules, and inorganic salts $[12,70,94,95]$. Peptides are the dominant components of most spider venoms, and many of these peptides target ion channels [12]. Spider-venom peptides are largely disulfide-rich molecules of 3.04.5 kDa in mass. The most common structural motif present in spider toxins is the inhibitor cystine knot (ICK), in which one of the disulfide bridges pierces a loop formed by the other two disulfide bonds and the intervening sections of the peptide backbone (i.e., Cys1-Cys4, Cys2-Cys5 and Cys3-Cys6; Figure 2A) [96-98]. One of the defining structural features of the ICK motif is a $\beta$-hairpin loop located in the C-terminal region. There are many variants of the ICK fold [82] including $\beta \beta$ (e.g., huwentoxin-IV and J-ACTX-Hv1c), $\beta \beta \beta$ (e.g., ACTX-Hi:OB4219), $3_{10} \beta \beta$ (e.g., hanatoxin 1), and $\beta \beta \beta 3_{10}$ (e.g., $\delta$ atracotoxin-Hv1) folds (Figure 2B). In the examples shown, an additional fourth disulfide bridge is located either in one of the loops or between a loop and the C-terminal region (highlighted in red; Figure $2 \mathrm{~B}$ ). The ICK motif provides these venom peptides with extraordinary stability by enhancing their resistance to chemical, thermal and proteolytic degradation [10, 99].

\section{Venom-derived modulators of epilepsy-related $\mathrm{Na}_{v}$ channels}




\section{1 $\mathrm{Na}_{\mathrm{v}}$ channel family and their biophysical properties}

Nav channels play a fundamental role in normal neurological function, especially in the initiation and propagation of action potentials (APs). They are composed of a large central pore-forming $\alpha$ subunit in complex with one or two auxiliary $\beta$ subunits [100]. In 1980, the first $\mathrm{Nav}$ channel $\alpha$ subunit was identified using scorpion toxins by photoaffinity labelling [101]. To date, nine pore-forming $\mathrm{Na}_{v}$ channel $\alpha$-subunits, denoted Nav1.1-1.9, have been cloned from mammals with $>50 \%$ identity in their transmembrane (TM) and extracellular domains [102]. They are all organised into four homologous but non-identical domains (DI-DIV), each containing six TM segments (S1-S6) joined by intracellular and extracellular linkers (Figure 3A). The S1-S4 segments constitute a voltage-sensing domain (VSD), while the S5-S6 segments from each domain come together to form the pore domain (Figure 3B).

Most venom peptides that modulate the activity of Nav channels are so-called "gating modifiers" that bind to one or more of the VSDs and alter the kinetics and/or voltage-dependence of channel activation and/or inactivation [103], although some are simple pore blockers that bind to the pore domain and sterically obstruct entry of $\mathrm{Na}^{+}$ions [104]. Recent advances in cryo-electron microscopy (cyro-EM) along with the ability of toxins to stabilise Nav channels in particular gating states has enabled 3D structures to be obtained for several eukaryotic Nav channels [e.g. [104-107]]. These structures have provided critical information about the binding sites for venom peptides that modulate Nav channel activity (Figure 3C).

Gating modifier toxins usually bind preferentially to one of the three basic gating states of the channel (i.e., open, closed and inactivated; Figure 3D). At the resting membrane potential ( -65 to $-75 \mathrm{mV}$ for most neurons), $\mathrm{Nav}$ channels remain in a closed conformation, where the activation gate is in a closed position and the inactivation gate is in an open position. Upon membrane depolarisation above threshold levels, the channels shift into an open conformation within milliseconds (a process called activation), resulting in the influx of sodium ions down their electrochemical gradient from the extracellular space to the cell interior. Within milliseconds after opening, the inactivation gate closes and $\mathrm{Nav}$ channels rapidly enter a non-conducting state via a process termed fast inactivation. Transient 
sodium ion influx through open $\mathrm{Nav}$ channels rapidly produces macroscopic current traces seen in whole-cell patch-clamp experiments (Figure 3E). This transient current is responsible for the rising phase of the AP in most excitable cells.

\subsection{Nav1.1-activating venom peptides for treatment of DS epilepsy}

Three $\mathrm{Na}_{\vee}$ channel $\alpha$ subunits, namely $\mathrm{Na}_{v} 1.1, \mathrm{Nav1.2}$ and $\mathrm{Nav1.6}$, have been reported to play pathogenetic roles in epilepsy (Table 1). Heterozygous LOF mutations in the Nav1.1 gene (SCN1A) are the main cause of DS [108]. In the brain, Nav1.1 is primarily found in the axon initial segments of fastspiking GABAergic inhibitory interneurons [109]. Thus, LOF mutations in SCN1A cause diminished $\mathrm{Na}_{v} 1.1$ currents and reduce the electrical excitability of GABAergic inhibitory interneurons. This perturbs the balance between excitation and inhibition in neural circuits throughout the brain and leads to hyperexcitability (Figure 4A,B) [110]. Therefore, frontline AEDs that inhibit Nav channels, such as carbamazepine, lamotrigine and phenytoin, are contraindicated in DS as they would lead to enhanced disinhibition and greater hyperexcitability of postsynaptic excitatory neurons (Figure 4A). Instead, a drug that activated the reduced population of functional Nav1.1 channels in DS interneurons might be a useful AED for this epilepsy as it would target the underlying molecular deficit.

To date, there are no small molecules that selectively activate Nav1.1. However, two paralogous peptides ( $\mathrm{Hm} 1 \mathrm{a}$ and $\mathrm{Hm} 1 \mathrm{~b}$ ) that selectively potentiate Nav1.1 were recently isolated from venom of the Togo starburst tarantula Heteroscodra maculata [111]. Hm1a/1b contain three disulfide bonds (Figure 4C) that form an ICK motif (Figure 4D). These peptides are gating modifiers that bind to the DIV VSD to inhibit fast inactivation of $\mathrm{Na}_{\mathrm{v}} 1.1$, which enhances the activity of the channel and leads to sustained currents (Figure 4E). Hm1a was able to restore the function of inhibitory interneurons from DS mice (i.e., transgenic mice with a human DS mutation), without affecting the firing of excitatory neurons, and intracerebroventricular infusion of Hm1a into DS mice abolished seizures within 4 days and dramatically increased overall survival [21].

It remains to be seen whether stimulation of Nav1.1 activity by inhibition of fast inactivation is the best 
approach for enhancing interneuron function in DS. For example, an alternative approach might be to stimulate channel activation. Scorpion-venom peptides were recently isolated that both inhibit channel inactivation and enhance channel activation [23]. While these venom peptides are not sufficiently selective for Nav1.1 to be useful as therapeutic leads, they nevertheless raise the possibility that venom peptides could be isolated with dual potentiating activity on Nav1.1 that might be useful for treatment of DS.

\subsection{Venom-peptide modulators of other $\mathrm{Na}_{v}$ channels involved in epilepsy}

A plethora of both LOF and GOF mutations in SCN2A (encoding the $\alpha$ subunit of the Nav1.2) and SCN8A (encoding the $\alpha$ subunit of the Nav1.6) are associated with familial epilepsies (Table 1). As mentioned previously, mutations of SCN2A have been identified in pedigrees with BFNIE, which is inherited in an autosomal dominant manner. BFNIE is characterised by early onset of multiple seizure types (i.e., focal and generalised onset seizures) and spontaneous remission in the first year of life $[112,113]$. A number of de novo SCN2A mutations have also been reported in patients with epileptic encephalopathy, including West syndrome, Otahara syndrome, Lennox-Gastaut syndrome, and autism spectrum disorder $[114,115]$. In addition, SCN8A mutations have been identified in patients with self-limited familial infantile epilepsy (formerly called benign familial infantile epilepsy, BFIE) and early-infantile epileptic encephalopathy type 13 (EIEE13) [56, 116, 117]. Unlike Nav1.1, which is found on interneurons, Nav1.2 and Nav1.6 are primarily localised to the axon initial segments of excitatory neurons in the cerebral cortex $[118,119]$. The relationship between functional alterations in these two channel subtypes and neuronal hyperexcitability remains to be determined. Given the primary expression patterns of $\mathrm{Na}_{\mathrm{v}} 1.2$ and $\mathrm{Nav1.6,} \mathrm{selective} \mathrm{pharmacological} \mathrm{inhibition} \mathrm{could,} \mathrm{in} \mathrm{principle,}$ counteract the imbalance between excitation and inhibition in the brain, and it explains why most frontline AEDs are Nav channel blockers.

There are numerous venom peptides that modulate the activity of Nav1.2 and Nav1.6, but none that are selective for these channels over other $\mathrm{Na}_{v}$ channel subtypes. Examples include the spider-venom 
peptides $\beta / \omega$-theraphotoxin-Tp2a (ProTx-II) from Thrixopelma pruriens and $\beta$-theraphotoxin-Ps1a (PaurTx-III) from Paraphysa scrofa, which inhibit activation of Nav1.2 and Nav1.6 (and other $\mathrm{Na}_{\mathrm{v}}$ channels) at low nanomolar concentrations [120-122]. While the lack of subtype selectivity precludes the use of these venom peptides as therapeutic leads, they have nevertheless proved useful as pharmacological tools. For example, PaurTx-III was recently used to delineate the role of Nav1.2 in brain excitability and febrile seizure generation [123]. Similarly, while venom peptides that activated Nav1.2 or Nav1.6 would be contraindicated in most epilepsies, they might be useful pharmacological tools. An interesting example of such a peptide is $\beta$-hexatoxin-Mg1a from the hexathelid spider Macrothele gigas which facilitates Nav1.2 channel opening by inducing a hyperpolarising shifting in the voltage dependence of activation [124].

\section{Venom-derived modulators of epilepsy-related voltage-gated potassium channels}

The voltage-gated potassium $\left(\mathrm{K}_{\mathrm{v}}\right)$ channel family comprises a functionally diverse group of $\mathrm{K}^{+}$-selective channels that are involved in a variety of physiological processes including maintenance and regulation of resting membrane potentials, repolarisation of neuronal and cardiac action potentials, regulation of $\mathrm{Ca}^{2+}$ signaling and cell volume, and promotion of cellular proliferation and migration [7]. Humans contain 40 genes encoding $K_{v}$ channels, which are divided into 12 subfamilies ( $\left.K_{v} 1 . x-K_{v} 12 . x\right)$ on the basis of amino acid sequence [7]. The prototypical $K_{v}$ channel has a tetrameric structure in which each subunit is composed of six TM segments denoted S1 to S6, reminiscent of one domain of $\mathrm{Na}_{\mathrm{v}}$ channels. Similar to $\mathrm{Na}_{v}$ channels, the $\mathrm{S} 5$ and $\mathrm{S} 6$ segments from each monomer of a $\mathrm{K}_{\mathrm{v}}$ channel cluster together in a circular formation to form the ion-permeation pathway across the cell membrane [125], while the remaining S1-S4 segments form four VSDs that surround the central pore [126].

Our current understanding of the ion selectivity and gating of $K_{v}$ channels has been significantly impacted by venom peptides. For example, a variety of pore-binding scorpion toxins were utilised to identify and characterise the pore-forming region of a $\mathrm{K}_{\mathrm{v}}$ channel protein [127-129]. This led to the use of venom peptides to measure the outer pore of $\mathrm{K}_{\mathrm{V}}$ channels as well as determine the subunit and 
functional stoichiometry of inactivation gates in a Shaker $\mathrm{K}^{+}$channel [130-133]. Venom peptides have also been used to examine the localisation and physiological roles of individual channel subtypes [134]. Many forms of epilepsy are associated with mutations in genes that encode $K_{v}$ channels (Table 1 ). One of the first $\mathrm{K}_{\mathrm{v}}$-related epilepsies discovered was episodic ataxia, which is caused by point mutations in the gene KCNA1 that encodes $\mathrm{K}_{v} 1.1$ [135]. Episodic ataxia is an autosomal dominant human disorder that produces persistent myokymia and attacks of generalized ataxia [135]. The generalised or focal onset seizures experienced by these patients are associated with a number of heterozygous LOF point mutations that alter channel function, most frequently by reducing current amplitude [135]. This discovery led to the identification of other $K_{v}$ channel mutations that cause epilepsy through a variety of different epileptogenic mechanisms. For example, mutations in the gene $K C N C 1$ that encodes $\mathrm{K}_{\mathrm{v} 3} 3.1$ lead to development of progressive myoclonus epilepsy due to the decreased excitability of fastspiking GABAergic interneurons [136], while mutations within KCNQ2, which encodes $\mathrm{K}_{\mathrm{v}} 7.2$, lead to various forms of epilepsy including self-limited familial neonatal epilepsy and vitamin B6-responsive epilepsy through reduction of the so-called $M$ current $[137,138]$.

Whilst $\mathrm{K}_{\mathrm{v}}$-related epilepsies are predominantly caused by reduced channel function, hyperactivity of $K_{v}$ channels can also cause epilepsy, such as in Temple-Baraitser Syndrome (TBS) and ZimmermanLaband Syndrome 1 (ZLS). TBS and ZLS are both multisystem developmental disorders characterised by refractory epilepsy, intellectual disability, facial dysmorphism and hypoplasia or aplasia of the nails of the thumb and great toe $[43,139,140]$. Due to the presence of early onset, intractable, generalised stiffening seizures, individuals affected by TBS and ZLS often have a short life expectancy and suffer from various other developmental disorders and comorbidities $[43,139]$. In TBS and ZLS patients, GOF mutations within the $K C N H 1$ gene that encodes $\mathrm{K}_{\mathrm{v}} 10.1$ lead to a reduced threshold for channel activation [43, 139]. This is proposed to cause faster neuronal firing and seizures [139].

There are currently no effective treatments for managing seizures in TBS/ZLS patients, and no targeted therapeutics in development. Known inhibitors of $K_{v} 10.1$ have either moderate selectivity but low 
potency (e.g., imipramine) or are moderately potent inhibitors of $\mathrm{K}_{v} 10.1$ but even better inhibitors of the closely related $K_{v} 11.1$ (hERG) channel (e.g., astemizole) [22]. Whilst $K_{v} 10.1$ is predominantly found in the brain, $\mathrm{K}_{\mathrm{v}} 11.1$ is primarily expressed in cardiac tissue where it plays a key role in determining the duration of the plateau phase of the cardiac action potential [141]. Inhibition of hERG can lead to long QT syndrome and enhanced risk of sudden death [141] and therefore the FDA mandates that all drug candidates be screened to ensure they do not inhibit this channel. Thus, development of AEDs that selectively inhibit $\mathrm{K}_{v} 10.1$ is likely to be extremely challenging because of its close homology with hERG.

Venom peptides are more likely to provide selective inhibition of Kv10.1 than small molecules and, moreover, they are more likely to be able to correct the hyperactive channel phenotype caused by TBS/ZLS mutations. These mutations cause a hyperpolarising shift in the voltage-dependence of channel activation $[43,139]$, so restoration of wild-type activity might be best achieved with a gating modifier peptide that has the opposite effect, rather than a pore blocker that simply inhibits the channel. With this in mind, Ma and colleagues performed an electrophysiological screen of arachnid venoms against $K_{v} 10.1$ and identified two spider-venom peptides (Aa1a and Ap1a) that shift the voltage-dependence of $\mathrm{K}_{\mathrm{v}} 10.1$ activation to more depolarised potentials, thereby counteracting the mutant phenotype [22]. Ap1a has good potency for $\mathrm{K}_{\mathrm{v}} 10.1$ (IC $\left.\mathrm{C}_{50} 236 \mathrm{nM}\right)$, 35-fold selectivity for $\mathrm{K}_{\mathrm{v}} 10.1$ over $\mathrm{K}_{\mathrm{v}} 11.1$, and it is exceptionally stable in human serum and cerebrospinal fluid due to its ICK architecture [22]. This combination of high potency and selectivity for $\mathrm{K}_{\mathrm{v}} 10.1$ and excellent stability in biological fluids makes Ap1a a useful lead for the development of $\mathrm{K}_{\mathrm{v}} 10.1$-targeted AEDs.

\section{Venom-derived modulators of epilepsy-related voltage-gated calcium channels}

Humans contain ten voltage-gated calcium (Cav) channels organised into three subfamilies (Cav1, Cav2 and Cav3). These channels have similar $\mathrm{Ca}^{2+}$ selectivity but different physiological functions [142]. The four subtypes of Cav1 channels (Cav1.1-Cav1.4) perform roles ranging from initiation of contraction and secretion in skeletal muscle to the regulation of gene expression, integration of synaptic input in neurons, and synaptic transmission at ribbon synapses in specialised sensory cells [143-145]. Cav2 
channels (Cav2.1-Cav2.3) initiate synaptic transmission at fast synapses, and they are involved in nociceptive signalling within the spinal cord [146], while members of the $\mathrm{Ca}_{\mathrm{v}} 3$ subfamily (Cav3.1-3.3) are involved in repetitive initiation of action potentials in rhythmically firing cells $[147,148]$. In general, functional Cav channels are a complex of several subunits: a transmembrane pore-forming $\alpha_{1}$ subunit, a membrane-attached $\alpha_{2} \delta$ subunit, an intracellular $\beta$ subunit and, in some cases, a transmembrane $\gamma$ subunit [149]. The $\alpha_{1}$ subunit, which has similar architecture to $\mathrm{Na}_{v}$ channels, forms the ion conducting pore. The associated subunits have variety of functions including modulation of the expression, trafficking, and electrophysiological and pharmacological properties of the channel $[150,151]$. The diversity in Cav channel structure ultimately leads to various voltage-gated $\mathrm{Ca}^{2+}$ currents with different physiological, pharmacological and regulatory properties.

Venom peptides have contributed significantly to the characterisation of $\mathrm{Ca}_{v}$ channels, and they are the defining pharmacology for some subtypes. For example, $\mathrm{Ca}_{\mathrm{v}} 2.2$ currents are characterised by their insensitivity to small-molecule Cav1 blockers and sensitivity to the cone snail venom-peptide $\omega$ conotoxin-GVIA [152]. P-type Cav2.1 currents are characterised by their sensitivity to the spider-venom peptide $\omega$-agatoxin-IVA [152]. Q-type currents mediated by a splice variant of $\mathrm{Ca}_{\mathrm{v}} 2.1$ can distinguished from P-type currents by their low affinity for $\omega$-agatoxin-IVA. Finally, $\mathrm{Ca}_{v} 2.3$ currents were identified by their resistance to most organic and peptidic $\mathrm{Ca}^{2+}$ channel inhibitors but high sensitivity to the spider-venom peptide SNX-482 [153]. Venom peptides have also contributed to the understanding of $\mathrm{Ca}_{v}$ channel structure and physiology. For instance, when $\omega$-conotoxin-GVIA was determined to selectively bind to Cav2.2 channels, it facilitated their purification and studies of their cellular localisation and roles in calcium entry, neurotransmitter release, and neuronal migration [154].

Due to their essential physiological role in signal transduction, various forms of epilepsy have been associated with mutations in Cav channels (Table 1). For example, the development of epileptic encephalopathy has been linked to LOF mutations in the CACNA1A gene that encodes the $\alpha_{1}$ subunit of Cav2.1 [155]. As noted above, Cav2.1 channels are important mediators of synaptic transmission. 
Reduced P/Q-type channel function could therefore lead to altered neurotransmitter release in cortical neurons, and reduce evoked excitatory synaptic potentials in thalamic neurons $[156,157]$.

Ancillary subunits regulate Cav channel function and membrane localisation of the pore-forming $\alpha 1$ subunit, so it is not surprising that mutations in the $\beta 4$ subunit of Cav2.1 are also associated with various forms of epilepsy, including juvenile myoclonic epilepsy [158]. GOF mutations within the CACNA1H gene that encodes the $\alpha 1$ subunit of $\mathrm{Ca}_{\mathrm{v}} 3.2$ have been linked to the development of both temporal lobe epilepsy and juvenile myoclonic epilepsy [159]. T-type channels are expressed in thalamic neurons with high densities, where they depolarise the membrane potential to generate lowthreshold spikes that trigger bursts of action potentials [160]. It remains to be determined how GOF Cav3.2 channels cause epilepsy in humans, but animal models suggested that elevated T-type currents might boost the excitatory postsynaptic potential, leading to an increase in intrinsic burst firing [161]. The venoms of most invertebrate predators are rich in Cav channel modulators [69]. Many cone-snail venom peptides have been isolated that target Cav channels [162], and one that selectively targets Cav2.2 has been developed as an intrathecal analgesic for management of intractable chronic pain [16]. Cav channel modulation is also the dominant pharmacology in spider venoms; about $45 \%$ of all described ion channel modulators from spider venom target these channels [163]. Some of these spider-venom peptides have exceptional subtype selectivity, such as $\omega$-agatoxin-IVA described above, while others have broader activity. For example, peptide PnTx3-6 (also known as Ph $\alpha 1 \beta, \mathrm{PhTx3}-6$ ) from venom of the lethal Brazilian armed spider Phoneutria nigriventer targets all $\mathrm{Ca}_{\mathrm{v}} 2$ subtypes $(\mathrm{N}, \mathrm{P} / \mathrm{Q}$, and R) [164] and it is in preclinical studies for treatment of numerous disorders including pain [165], multiple sclerosis [166], pruritus [167], and glioma [168]. We are unaware of any venom peptides that target $\mathrm{Ca}_{v}$ channels being studied in the context of epilepsy, but the diversity of Cav channel modulators in animal venoms suggests they may be a valuable source of pharmacological tools and therapeutic leads for Cav channel-related epilepsies.

\section{Epilepsy related ligand-gated ion channels and their toxin modulators}




\subsection{Ligand-gated ion channels - the largest epilepsy related channel group}

Rapid electrical signalling initiated by ligand binding is an essential component of neural activation. This process is mediated by families of ligand-gated ion channels (LGICS) that convert the chemical stimulus of ligand binding to an electrical current across a cell through an intrinsic ion channel. LGICs perform both excitatory and inhibitory functions in the CNS, depending on the electrochemical gradient of the neuron and the selectivity of the channel. They are grouped into families based on structural similarities, and include trimeric, tetrameric and pentameric receptors (Figure 5).

\subsubsection{Cys-Loop Receptors}

Cys-loop receptors mediate both excitatory and inhibitory synaptic transmission, converting presynaptic chemical neurotransmitter release into postsynaptic electrical signals. They are defined by a common quaternary structure of five subunits symmetrically or pseudosymmetrically arranged around a central ion-conducting pore. Many, but not all, Cys-loop receptors contain a signature Cysloop in the extracellular domain, which gives the superfamily its name [169]. Mammalian members of this superfamily include the nicotinic acetylcholine receptor (nAChR), $\mathrm{p}$-aminobutyric acid type $A$ $\left(\mathrm{GABA}_{\mathrm{A}}\right)$ receptor, glycine (Gly) receptor, and 5- $\mathrm{HT}_{3}$ (serotonin) receptor [169]. Related glutamategated chloride channels (GluCl) are found in invertebrates [170]. Each subunit has a prototypical tertiary structure consisting of a large $\mathrm{N}$-terminal extracellular domain, four TM $\alpha$-helices (M1-M4) connected by a short intracellular M1-M2 and extracellular M2-M3 loops and a larger intracellular M3M4 loop, and a short extracellular C-terminal domain (Figure 5A, 5D) [169]. The pore of the channel is surrounded by amino acids of the M2 domain, and it conducts $\mathrm{Na}^{+} / \mathrm{Ca}^{+}$ions in the case of $\mathrm{nAChR}$ and 5- $\mathrm{HT}_{3 \mathrm{~A}}$ receptors, and chloride ions in the case of $\mathrm{GABA}_{A}$, Gly and $\mathrm{GluCl}$ receptors [171].

The neuronal $n A C h R$ and $G_{A B A}$ receptors are known for their rich pharmacology that is determined both by the large subunit heterogeneity, and the presence of orthosteric and allosteric binding sites that make them suitable drug targets [172]. Human genome sequencing has identified at least 19 
$\mathrm{GABA}_{A}$ receptor subunit genes ( $\alpha 1-6, \beta 1-3, \gamma 1-3, \delta, \varepsilon, \theta, \pi$ and $\left.\rho 1-3\right)$, while the neuronal nAChRs can be formed from combination of $\alpha 2-\alpha 7, \alpha 9-\alpha 10$, and $\beta 2-\beta 4$ subunits [173] .

All mammalian pLGICS have a native ligand-binding site in the extracellular domain at the interface between two subunits [174]. In addition, there are multiple allosteric binding sites in the extracellular domain and within the TM regions where positive allosteric modulators such as barbiturates, neurosteroids and general anesthetics can bind. Antagonists also bind at a variety of sites within the extracellular domain, the channel pore, and other sites within the TM regions [175].

\subsubsection{Ionotropic glutamate receptors}

The ionotropic glutamate receptors (iGluRs) mediate the majority of excitatory neurotransmission in the CNS. Members of this family of receptors include the $\alpha$-amino-3-hydroxy-5-methyl-4isoxazolepropionic acid (AMPA), N-methyl-D-aspartate (NMDA), and kainaite receptors [176]. These receptors have a distinct modular structure that differs from that of the Cys-loop receptors. iGluRs are tetrameric with four domains arranged in distinct domain layers including the extracellular $\mathrm{N}$-terminal domain (NTD), a ligand-binding domain (LBD), a TM region, and a cytosolic C-terminal domain [177]. The extracellular domains of the iGluR form a dimer of intertwined dimers, while the channel pore is a symmetrical or pseudosymmetrical arrangement of subunits around the central cation-conducting pore [178]. In contrast to the Cys-loop receptors, the ligand-binding domains are located within single subunits rather than the subunit interface (Figure 5B,E). Glutamate binds between two domains, D1 and D2, within the ligand-binding domain. NMDA receptors also require glycine as a co-agonist for channel gating $[177,179]$. The pharmacology of NMDA and AMPA receptors encapsulates positive allosteric modulators and antagonists that bind at sites distinct from the glutamate, or glycine, binding site to alter the opening of the channel [177].

\subsection{3 $\mathrm{P} 2 \mathrm{X}$ receptors}

The P2X receptors are a family of ATP-gated ion channels involved in purinergic signalling. There are seven mammalian subunits, $\mathrm{P} 2 \mathrm{X} 1-7$ that can assemble into homo- or heterotrimers that play a role in 
physiological processes as diverse as smooth muscle contraction, synaptic transmission, inflammation, hearing, and taste [180]. Structurally, there are several distinct domains: an extracellular domain that contains the ligand binding site; two TM helices that form a non-selective cation-conducting pore; and $\mathrm{N}$ - and C-terminal intracellular domains (Figure 5C,F). The pharmacology of P2X receptors includes different sensitivities of the receptors to ATP and ATP analogs, and a variety of selective small molecule antagonists [180]. P2X receptors have not been asscociated with genetic epilepsies, so we focus here on the tetramic and pentameric LGICs.

\subsection{LGICs and genetic epilepsies}

Next-generation sequencing has enabled identification of a host of genes previously not known to be associated with epilepsy, including many encoding for diverse LGICs subunits, in addition to those discovered through familial studies and rational gene discovery approaches. Variants in genes encoding $\mathrm{GABA}_{A}, \mathrm{nAChR}, \mathrm{AMPA}$ and NMDA subunits have all been associated with various epilepsies.

\subsubsection{Genetic epilepsies of $G A B A_{A}$ Receptors}

$\mathrm{GABA}_{\mathrm{A}}$ receptors form chloride channels, most often mediating chloride influx into neuronal cells to inhibit neuronal activity when activated. The classical view of $\mathrm{GABA}_{A}$ receptors is the role they perform in synaptic inhibition. For instance, in inhibitory GABAergic interneurons an action potential propagated by $\mathrm{Na}_{\mathrm{v}} 1.1$ channels initiates the release of high concentrations of GABA across the synaptic cleft. GABA then binds to $\mathrm{GABA}_{A}$ receptors on postsynaptic neurons to initiate a conformational change that is propagated through to the TM region to open an intrinsic chloride channel. The influx of chloride then hyperpolarises the cell membrane, inhibiting the neuron and reducing neuronal activity.

After $\mathrm{Na}_{V}$ channels, genes encoding $\mathrm{GABA}_{\mathrm{A}}$ receptors are some of the most frequently identified variants that cause childhood epilepsies. Like most genetic epilepsies, there is a considerable range of severity for patients with variants in the same gene, from mild absence seizures to the severe epileptic encephalopathies and DS [181] (Table I). Initially, variants were discovered in $\gamma 2$ and $\alpha 1$ subunits that

impaired receptor activation [182, 183]. Later, studies of de novo patients from the EpiK consortium 
discovered variants in the $\beta 3$ subunit associated with epileptic encephalopathies, developmental delay and movement disorders [184]. Today, genetic variants in the $\alpha 1, \alpha 2, \alpha 3, \alpha 5, \alpha 6, \beta 1, \beta 2, \beta 3$ and $\gamma 2$ subunits have been associated with de novo epileptic encephalopathies, with the likelihood of more subunits to follow.

The general consensus is that a reduction in GABAergic inhibitory transmission is the underlying cause of seizures in $\mathrm{GABA}_{\mathrm{A}}$ genetic epilepsies. Importantly, patients with these variants are often refractory to therapeutic intervention; although GABAergic drugs are available for therapeutic use, including several indicated for epilepsy, there is an unmet clinical need for better therapies for these patients.

\subsubsection{Genetic epilepsies of nAChRs}

The first example of a genetically transmissible form of epilepsy through a variant in a gene encoding an LGIC was CHRNA4, the gene that encodes the $\alpha 4$ subunit that is incorporated into the major neuronal nAChR subtype, $\alpha 4 \beta 2$ [42]. Subsequently, variants were identified in the $\alpha 2, \alpha 4$ and $\beta 2$ subunits that cause autosomal dominant nocturnal frontal lobe epilepsy (ADNFLE), a disorder characterised by seizures that are usually nocturnal, lasting for a few seconds to a several minutes [185].

ADNFLE-associated variants are GOF mutations, with increased currents elicited by acetylcholine [186]. The $\alpha 4 \beta 2$ nAChR exists in two stoichiometries: $2 \alpha 4: 3 \beta 2$ that contains two high-affinity sites for ACh, and $3 \alpha 4: 2 \beta 2$ that contains an additional low-affinity site for ACh [187]. Generally, epilepsy-associated variants cause increased receptor activation when either two or three ACh molecules are bound, regardless of stoichiometry [188].

\subsubsection{Genetic epilepsies of iGluRs}

The extremely rapid, sub-millisecond gating kinetics of AMPA receptors allows fast propagation of signals between nerve cells. Recent genetic evidence strongly implicates LOF and/or altered $\mathrm{Ca}^{2+}$ permeability of GluA2 variants with seizures, epileptic encephalopathies, intellectual disability and 
neurodevelopmental disorders such as autism spectrum disorder, but it is not yet clear how these variants lead to the development of seizures [189].

NMDA receptors mediate a slow component of synaptic excitatory neurotransmission in the brain and CNS, predominantly through $\mathrm{Ca}^{2+}$ flux. There is clear genetic evidence that associates NMDA receptors with epileptic encephalopathies, with de novo variants identified in the GRIN1, GRIN2A, GRIN2B and GRIN2D genes that encode the GluN1, GluN2A, GluN2B and GluN2D subunits, respectively [190]. In vitro electrophysiological studies of these variants have revealed that some enhance agonist potency, decrease sensitivity to negative modulators including magnesium, protons and zinc, prolong the synaptic response time course, and increase single-channel open probability, suggesting increased NMDA receptor activation and neuronal hyperexcitability [191]. However, other variants, including truncation mutants, appear to cause LOF, indicating that the subunit composition of NMDA receptors is critical for normal neurodevelopment [192]. Interestingly, a patient with the GluN2D p.Val667lle variant that increases glutamate and glycine potency by 2 -fold and increases channel open probability by 6 -fold, responded well to adjunct therapy with memantine, a voltage-dependent, low-affinity uncompetitive blocker of NMDA receptors [193]. This demonstrates the potential for NMDA receptor antagonists to be used as precision AEDs for specific variants.

\subsection{Therapeutic potential of venom peptides that target LGICs}

\subsection{1 $\mathrm{GABA}_{\mathrm{A}}$ receptors}

$\mathrm{GABA}_{\mathrm{A}}$ receptors are attractive drug target for several reasons, including their role in neuronal inhibition, their remarkable subunit heterogeneity, and the presence of multiple allosteric drug binding sites located at the interface between different subunits [194]. As such, GABA $A$ receptors have long been known as effective AED targets for the treatment of seizures. Positive allosteric modulators of $G_{A B A_{A}}$ receptors are still routinely used in the treatment of life-threatening status epilepticus, including the benzodiazepines diazepam, lorazepam and midazolam, the barbiturates phenobarbital and pentobarbital, and the general anaesthetic propofol [194]. Additionally, the GABAergic system is 
a target of adjunct therapies. As previously described, in DS, two important recent drug additions to the clinic, stiripentol and cannabidiol, are modulators not just of $\mathrm{GABA}_{\mathrm{A}}$ receptors per se, but also the activity of benzodiazepines $[195,196]$. In both cases, the drugs inhibit the enzymatic breakdown of the anticonvulsant as well as being positive allosteric modulators of $G A B A_{A}$ receptors. When searching for venom peptides that target $\mathrm{GABA}_{\mathrm{A}}$ receptors, the usefulness of a peptide that enhances the activity or increases the concentrations of known AEDs should not be overlooked.

Although many venom peptides have been isolated that target LGICs, relatively few have been shown to target $\mathrm{GABA}_{\mathrm{A}}$ receptors. However, two disulfide-rich venom peptides (MmTX1 and MmTX2) from venom of the Costa Rican coral snake Micrurus mipartitus [197] are selective ligands at $G A B A_{A}$ receptors. MmTx1 paralysed wild-type Caenorhabditis elegans, but not a C. elegans variant with a disruption of the gene encoding for the $G A B A_{A}$ receptor. Competition-binding experiments in rat synaptosomes demonstrated that $M m T x 1$ is selective for $G_{A B A}$ receptors and competes with muscimol, a potent agonist of $\mathrm{GABA}_{A}$ [197]. MmTx1 is a positive allosteric modulator of $\mathrm{GABA}_{A}$ receptors recombinantly expressed in HEK293 cells, and it also prolongs the deactivated state of the receptor. When injected into mouse brain, the consequences of this pharmacological mechanism is clear, with initial periods of reduced basal activity, followed by bursts of intense seizures, demonstrating the potent proconvulsant effect of increased $\mathrm{GABA}_{A}$ receptor desensitisation [197],; this phenomenon also occurs in patients with epilepsy-causing variants in $G A B A_{A}$ receptors that increase desensitisation [198]. For venom peptides that target $\mathrm{GABA}_{A}$ receptors to be effective AEDS, they need to have the correct pharmacodynamic (PD) profile, with the desired receptor selectivity and be true positive allosteric modulators, even before the complex requirements of pharmacokinetics (PK) and brain penetration are even considered. Nevertheless, the rich diversity of LGIC modulators found in animal venoms makes them a promising source to find a lead compound with the right pharmacological and PK/PD profile.

\subsection{2 nAChRs}


Genetic and pharmacological evidence for the role of nACh receptors in the pathophysiology of epilepsy has largely been restricted to mild ADNFLE. In this disorder, it is thought that increased ACh sensitivity causes an unbalance in fine-tuning of the cortico-reticular thalamic and thalamocortical loops, leading to abnormal synchronisation of neuronal networks initiating seizures [199]. No modulators of $\mathrm{nACh}$ receptors are in clinical use, however lamotrigine, an AED that primarily works as a $\mathrm{Na}_{v}$ channel blocker, has also been reported to block $\alpha 4 \beta 2 \mathrm{nACh}$ receptors [200]. Notably, the smoking-cessation drug varenicline, a partial agonist of $\alpha 4 \beta 2 \mathrm{nACh}$ receptors, contains a black box warning for seizure induction as an adverse effect [201].

An inherent problem in developing therapeutically useful nAChR modulators is that subtype selectivity is essential for a drug to be clinically useful [202]. Compounds that inhibit muscle-type nACh receptors at the neuromuscular junction, such as the potent snake toxin $\alpha$-bungarotoxin, would be dangerous as they could cause paralysis and respiratory failure [203]. While toxins that inhibit these receptors are ideal for prey capture, ligands that are selective for the structurally similar nAChR subtypes expressed in the brain are required for therapeutic use [204]. Fortunately, animal venoms are an abundant source nAChR modulators, including the most subtype-selective nAChR ligands discovered to date $[205,206]$. The largest group of venom peptides that target nAChRs are the $\alpha$-conotoxins derived from venomous marine cone snails (genus Conus). These two-disulfide peptides that have a characteristic C-C- $\mathrm{X}_{m}-\mathrm{C}-\mathrm{X}_{n}$ framework. Some $\alpha$-conotoxins have exceptional subtype selectivity and are used as the defining pharmacology for some nAChR subtypes $[205,206]$. While other venomous animals such as scorpions [207], snakes [204, 208], and spiders [209] also contain peptides that modulate nAChRs, they mostly lack the subtype selectivity of the $\alpha$-conotoxins.

Although venom peptides that target specific nAChR subtypes are promising therapeutic leads, they are more likely to be developed for indications other than epilepsy [210]. nAChRs appear to play a less important role in the pathogenesis of seizures than other ion channels, as shown by the less severe phenotypes of patients with variants in nAChR subunits. 


\subsubsection{AMPA receptors}

Glutamate is the major excitatory neurotransmitter in the brain, and iGluRs, including AMPA receptors (AMPARs), mediate the majority of glutamatergic neurotransmission. In the 1990 s, there was great interest in the iGluRs as a target for AEDs, with NMDA receptors thought to play a pivotal role in the initiation of seizures [211]. It was demonstrated that seizure activity in some in vivo and in vitro epilepsy models was suppressed by NMDA receptor antagonists, however in most slice models, both NMDA and non-NMDA receptors had to be blocked to fully suppress epileptiform discharges. Indeed, in certain models, simply blocking non-NMDA receptors was sufficient [212-214]. NMDA receptor activity was found to be critical in synaptic plasticity with a key role in long-term potentiation, altering the expression and type of AMPA receptors expressed at the cell surface. Therefore, the selectivity of antagonists for AMPA over NMDA receptors is extremely important in the development of therapeutics, and this culminated in the approval of perampanel, a non-competitive antagonist of AMPARs, as an AED [215].

Venoms may be a useful source of selective AMPAR antagonists with anti-epileptic effects. Several classes of venom toxins target AMPARs, including polyamine toxins from spiders and wasps that are use-dependent blockers of AMPARs; these toxins are widely employed as potent antagonists of receptor subtypes lacking GluA2 subunits [216]. For instance, the polyamine toxins JSTX-3, NPTX-1 and NPTX-8 from venom of the orb-weaving spider Trichonephila clavata are potent but non-selective blockers of iGluRs. JSTX-3 blocks induced epileptiform activity in rat hippocampal neurons, but its action appears to be mediated, at least in part, via NMDA receptors [217].

To be therapeutically useful AEDS, venom compounds that target iGluRs would need display high selectivity for specific subtypes, and there is some evidence that such compounds might be found in animal venoms. For example, peptide PnTx4-5-5 isolated from the venom of the spider $P$. nigriventer selectively inhibits NMDA receptors with little to no activity on other iGluRs [218]. High-throughput screening of venoms against specific iGLuR subtypes might uncover more peptides with potential as pharmacological tools or therapeutic leads for iGluR-related epilepsies. 


\section{Conclusions and future perspectives}

Precision epilepsy therapy relies on therapeutics that target the underlying pathological defect, which is often an ion channel. Even though ion channels have become the third most common human drug target after kinases and G-protein-coupled receptors [219], development of ion channel drugs is often extremely challenging. A major challenge in AED development is avoidance of side-effects caused by both on-target and off-target mechanisms. For example, deleterious side-effects could be caused by activity on target ion channels outside of the pathological neuron types or brain areas, or by excessive activity on the targeted channel in the brain. For example, one might predict that pharmacological over-stimulation of Nav1.1 channels in the context of DS might lead to excessive inhibition of excitatory neurons, leading to sedation or more serious side-effects. Another major difficulty is achieving subtype selectivity when there are several homologous members within an ion channel family. Again in the context of DS, an agonist that stimulated Nav1.2 in excitatory neurons in addition to Nav1.1 in inhibitory neurons might worsen the epileptic phenotype by leading to even higher level of excitability [21]. Achieving subtype selectivity is particularly difficult for small-molecule drugs, because they provide only a small interaction surface with the target channel. Biologics, represented by antibodies and peptides, enable more extensive interactions with the target channel because of their much larger size and consequently they often provide better potency and subtype selectivity. Biologics have therefore become a growing trend in ion channel drug discovery [220].

Animal venoms are rich in disulfide-stabilised peptides that have been evolutionarily tuned over tens to hundreds of millions of years to target ion channels with exceptional potency and selectivity. Modern proteomic and transcriptomic technologies enable venom peptidomes to be elucidated rapidly using minute amounts of venom [221-223], and high-throughput screening techniques allow rapid identification of venom peptides with activity against ion channel targets [83, 224, 225]. Crucially, automated electrophysiology platforms now enable identification of state-dependent modifiers of the target channel, which is not achievable with imaging-based assays. For example, it may be preferable to target the open or inactivated state of Nav channels to achieve use-dependent modulation, whereas 
it might be better to identify activators that target the closed state of $\mathrm{K}_{v}$ channels in which LOF mutations are implicated in epilepsy. Thus, although the application of venom peptides to the study and treatment of epilepsy is in its infancy, there is huge potential for the discovery of venom peptides that selectively modulate the activity of epilepsy-related ion channels. Regardless of their therapeutic potential, many of these peptides are likely to be useful pharmacological tools for dissecting the physiological role of these ion channels and their contribution to seizure development in epilepsy.

\section{Acknowledgements}

We gratefully acknowledge funding support from the Australian National Health \& Medical Research Council (Principal Research Fellowship APP1136889 and Program Grant APP1072113 to G.F.K.; C.J. Martin Fellowship APP1035102 to L.M., Ideas Grant APP1185122 to N.A.), Citizen's United for Research in Epilepsy (Pediatric Epilepsies Award 353711 to G.F.K.), Lambert Initiative for Cannabinoid Therapeutics (grant to N.A.), and The University of Queensland (International Postgraduate Scholarship to C.Y.C.). 


\section{References}

[1] Goldberg EM, Coulter DA, Mechanisms of epileptogenesis: a convergence on neural circuit dysfunction, Nat Rev Neurosci 14 (2013) 337-349.

[2] Fisher RS, van Emde Boas W, Blume W, Elger C, Genton P, Lee P, et al., Epileptic seizures and epilepsy: definitions proposed by the International League Against Epilepsy (ILAE) and the International Bureau for Epilepsy (IBE), Epilepsia 46 (2005) 470-472.

[3] Moshé SL, Perucca E, Ryvlin P, Tomson T, Epilepsy: new advances, Lancet 385 (2015) 884-898.

[4] Billakota S, Devinsky O, Kim KW, Why we urgently need improved epilepsy therapies for adult patients, Neuropharmacology (2019) 107855.

[5] Mohanraj R, Norrie J, Stephen L, Kelly K, Hitiris N, Brodie MJ, Mortality in adults with newly diagnosed and chronic epilepsy: a retrospective comparative study, Lancet Neurol 5 (2006) 481-487.

[6] Wang J, Lin ZJ, Liu L, Xu HQ, Shi YW, Yi YH, et al., Epilepsy-associated genes, Seizure 44 (2017) 11-20.

[7] Hille B. Ion channels of excitable membranes. Sunderland, USA: Sinauer Associates, 2001.

[8] Wei F, Yan LM, Su T, He N, Lin ZJ, Wang J, et al., Ion Channel genes and epilepsy: functional alteration, pathogenic potential, and mechanism of epilepsy, Neurosci Bull 33 (2017) 455-477.

[9] King GF, Venoms as a platform for human drugs: translating toxins into therapeutics, Expert Opin Biol Ther 11 (2011) 1469-1484.

[10] Saez NJ, Senff S, Jensen JE, Er SY, Herzig V, Rash LD, et al., Spider-venom peptides as therapeutics, Toxins (Basel) 2 (2010) 2851-2871.

[11] Kalia J, Milescu M, Salvatierra J, Wagner J, Klint JK, King GF, et al., From foe to friend: using animal toxins to investigate ion channel function, J Mol Biol 427 (2015) 158-175.

[12] King GF, Hardy MC, Spider-venom peptides: structure, pharmacology, and potential for control of insect pests, Annu Rev Entomol 58 (2013) 475-496.

[13] King GF, Tying pest insects in knots: the deployment of spider-venom-derived knottins as bioinsecticides, Pest Manag Sci 75 (2019) 2437-2445. 
[14] Lewis RJ, Garcia ML, Therapeutic potential of venom peptides, Nat Rev Drug Discov 2 (2003) 790802.

[15] Pennington MW, Czerwinski A, Norton RS, Peptide therapeutics from venom: current status and potential, Bioorg Med Chem 26 (2018) 2738-2758.

[16] Sanford M, Intrathecal ziconotide: a review of its use in patients with chronic pain refractory to other systemic or intrathecal analgesics, CNS Drugs 27 (2013) 989-1002.

[17] Nunes KP, Torres FS, Borges MH, Matavel A, Pimenta AM, De Lima ME, New insights on arthropod toxins that potentiate erectile function, Toxicon 69 (2013) 152-159.

[18] Yang S, Xiao Y, Kang D, Liu J, Li Y, Undheim EA, et al., Discovery of a selective Nav1.7 inhibitor from centipede venom with analgesic efficacy exceeding morphine in rodent pain models, Proc Natl Acad Sci USA 110 (2013) 17534-17539.

[19] Chassagnon IR, McCarthy CA, Chin YK, Pineda SS, Keramidas A, Mobli M, et al., Potent neuroprotection after stroke afforded by a double-knot spider-venom peptide that inhibits acidsensing ion channel 1a, Proc Natl Acad Sci USA 114 (2017) 3750-3755.

[20] de Souza JM, Goncalves BDC, Gomez MV, Vieira LB, Ribeiro FM, Animal toxins as therapeutic tools to treat neurodegenerative diseases, Front Pharmacol 9 (2018) 145.

[21] Richards KL, Milligan CJ, Richardson RJ, Jancovski N, Grunnet M, Jacobson LH, et al., Selective Nav1.1 activation rescues Dravet syndrome mice from seizures and premature death, Proc Natl Acad Sci USA 115 (2018) E8077-E8085.

[22] Ma L, Chin YKY, Dekan Z, Herzig V, Chow CY, Heighway J, et al., Novel venom-derived inhibitors of the human EAG channel, a putative antiepileptic drug target, Biochem Pharmacol 158 (2018) 60-72.

[23] Chow C, Chin Y, Walker A, Guo S, Blomster L, Ward M, et al., Venom peptides with dual modulatory activity on the voltage-gated sodium channel Nav1.1 provide novel leads for development of antiepileptic drugs, ACS Pharmacol Transl Sci 3 (2020) 119-134. 
[24] World Health Organisation. Epilepsy: a public health imperatiEve. Available online at https://www.who.int/mental health/neurology/epilepsy/report 2019/en/, 2019.

[25] Forsgren L, Hauser WA, Olafsson E, Sander JW, Sillanpaa M, Tomson T, Mortality of epilepsy in developed countries: a review, Epilepsia 46 Suppl 11 (2005) 18-27.

[26] Lhatoo SD, Sander JW, Cause-specific mortality in epilepsy, Epilepsia 46 Suppl 11 (2005) 36-39.

[27] Hansen J, Åsberg S, Kumlien E, Zelano J, Cause of death in patients with poststroke epilepsy: results from a nationwide cohort study, PLoS ONE 12 (2017) e0174659.

[28] Luyken C, Blumcke I, Fimmers R, Urbach H, Elger CE, Wiestler OD, et al., The spectrum of long-term epilepsy-associated tumors: long-term seizure and tumor outcome and neurosurgical aspects, Epilepsia 44 (2003) 822-830.

[29] Hirtz D, Thurman DJ, Gwinn-Hardy K, Mohamed M, Chaudhuri AR, Zalutsky R, How common are the "common" neurologic disorders?, Neurology 68 (2007) 326-337.

[30] Logroscino G, Hesdorffer DC, Cascino GD, Annegers JF, Bagiella E, Hauser WA, Long-term mortality after a first episode of status epilepticus, Neurology 58 (2002) 537-541.

[31] Tomson T, Mortality in epilepsy, J. Neurol. 247 (2000) 15-21.

[32] Pereda AE, Electrical synapses and their functional interactions with chemical synapses, Nat Rev Neurosci 15 (2014) 250-263.

[33] Holmes GL, Role of glutamate and GABA in the pathophysiology of epilepsy, Ment Retard Dev Disabil Res Rev 1 (1995) 208-219.

[34] Cope DW, Di Giovanni G, Fyson SJ, Orban G, Errington AC, Lorincz ML, et al., Enhanced tonic GABA inhibition in typical absence epilepsy, Nat Med 15 (2009) 1392-1398.

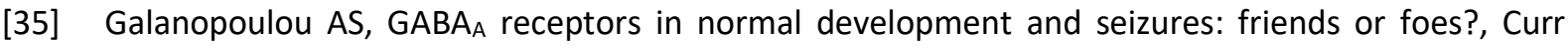
Neuropharmacol 6 (2008) 1-20.

[36] Ben-Ari Y, Excitatory actions of GABA during development: the nature of the nurture, Nat Rev Neurosci 3 (2002) 728-739. 
[37] Zhang Z, Jiao YY, Sun QQ, Developmental maturation of excitation and inhibition balance in principal neurons across four layers of somatosensory cortex, Neuroscience 174 (2011) 10-25.

[38] Thijs RD, Surges R, O'Brien TJ, Sander JW, Epilepsy in adults, Lancet 393 (2019) 689-701.

[39] Berg AT, Mathern GW, Bronen RA, Fulbright RK, DiMario F, Testa FM, et al., Frequency, prognosis and surgical treatment of structural abnormalities seen with magnetic resonance imaging in childhood epilepsy, Brain 132 (2009) 2785-2797.

[40] Helbig I, Scheffer IE, Mulley JC, Berkovic SF, Navigating the channels and beyond: unravelling the genetics of the epilepsies, Lancet Neurol 7 (2008) 231-245.

[41] Blumenfeld H, Varghese GI, Purcaro MJ, Motelow JE, Enev M, McNally KA, et al., Cortical and subcortical networks in human secondarily generalized tonic-clonic seizures, Brain 132 (2009) 9991012.

[42] Steinlein OK, Mulley JC, Propping P, Wallace RH, Phillips HA, Sutherland GR, et al., A missense mutation in the neuronal nicotinic acetylcholine receptor $\alpha 4$ subunit is associated with autosomal dominant nocturnal frontal lobe epilepsy, Nat Genet 11 (1995) 201-203.

[43] Simons C, Rash LD, Crawford J, Ma L, Cristofori-Armstrong B, Miller D, et al., Mutations in the voltagegated potassium channel gene $K C N H 1$ cause Temple-Baraitser syndrome and epilepsy, Nat Genet 47 (2015) 73-77.

[44] Koh HY, Lee JH, Brain somatic mutations in epileptic disorders, Mol Cells 41 (2018) 881-888.

[45] Bae T, Tomasini L, Mariani J, Zhou B, Roychowdhury T, Franjic D, et al., Different mutational rates and mechanisms in human cells at pregastrulation and neurogenesis, Science 359 (2018) 550-555.

[46] Reid CA, Berkovic SF, Petrou S, Mechanisms of human inherited epilepsies, Prog Neurobiol 87 (2009) 41-57.

[47] Harrill JA, Chen H, Streifel KM, Yang D, Mundy WR, Lein PJ, Ontogeny of biochemical, morphological and functional parameters of synaptogenesis in primary cultures of rat hippocampal and cortical neurons, Mol Brain 8 (2015) 10. 
[48] Parent JM, Anderson SA, Reprogramming patient-derived cells to study the epilepsies, Nat Neurosci 18 (2015) 360-366.

[49] Guerrini R, Marini C, Mantegazza M, Genetic epilepsy syndromes without structural brain abnormalities: clinical features and experimental models, Neurotherapeutics 11 (2014) 269-285.

[50] Kandratavicius L, Balista PA, Lopes-Aguiar C, Ruggiero RN, Umeoka EH, Garcia-Cairasco N, et al., Animal models of epilepsy: use and limitations, Neuropsychiatr Dis Treat 10 (2014) 1693-1705.

[51] Helbig I, Lowenstein DH, Genetics of the epilepsies: where are we and where are we going?, Curr Opin Neurol 26 (2013) 179-185.

[52] Meng H, Xu HQ, Yu L, Lin GW, He N, Su T, et al., The SCN1A mutation database: updating information and analysis of the relationships among genotype, functional alteration, and phenotype, Hum Mutat 36 (2015) 573-580.

[53] Ramadan W, Patel N, Anazi S, Kentab AY, Bashiri FA, Hamad MH, et al., Confirming the recessive inheritance of SCN1B mutations in developmental epileptic encephalopathy, Clin Genet 92 (2017) $327-331$.

[54] Shen D, Hernandez CC, Shen W, Hu N, Poduri A, Shiedley B, et al., De novo GABRG2 mutations associated with epileptic encephalopathies, Brain 140 (2017) 49-67.

[55] Misra SN, Kahlig KM, George AL, Jr., Impaired Nav1.2 function and reduced cell surface expression in benign familial neonatal-infantile seizures, Epilepsia 49 (2008) 1535-1545.

[56] Scheffer IE, Berkovic S, Capovilla G, Connolly MB, French J, Guilhoto L, et al., ILAE classification of the epilepsies: position paper of the ILAE Commission for Classification and Terminology, Epilepsia 58 (2017) 512-521.

[57] Niday Z, Tzingounis AV, Potassium channel gain of function in epilepsy: an unresolved paradox, Neuroscientist 24 (2018) 368-380.

[58] Gaitatzis A, Sander JW, The long-term safety of antiepileptic drugs, CNS Drugs 27 (2013) 435-455. 
[59] Perucca E, Meador KJ, Adverse effects of antiepileptic drugs, Acta Neurol Scand Suppl 181 (2005) $30-35$.

[60] Perucca E, Tomson T, The pharmacological treatment of epilepsy in adults, Lancet Neurol 10 (2011) 446-456.

[61] French JA, Staley BA, AED treatment through different ages: as our brains change, should our drug choices also?, Epilepsy Curr 12 (2012) 22-27.

[62] Mallet L, Spinewine A, Huang A, The challenge of managing drug interactions in elderly people, Lancet 370 (2007) 185-191.

[63] Kwan P, Brodie MJ, Early identification of refractory epilepsy, N Engl J Med 342 (2000) 314-319.

[64] Picot MC, Baldy-Moulinier M, Daures JP, Dujols P, Crespel A, The prevalence of epilepsy and pharmacoresistant epilepsy in adults: a population-based study in a Western European country, Epilepsia 49 (2008) 1230-1238.

[65] Dravet C, Bureau M, Oguni H, Fukuyama Y, Cokar O, Severe myoclonic epilepsy in infancy: Dravet syndrome, Adv Neurol 95 (2005) 71-102.

[66] Dravet C, The core Dravet syndrome phenotype, Epilepsia 52 Suppl 2 (2011) 3-9.

[67] Perez J, Chiron C, Musial C, Rey E, Blehaut H, d'Athis P, et al., Stiripentol: efficacy and tolerability in children with epilepsy, Epilepsia 40 (1999) 1618-1626.

[68] Koh CY, Kini RM, From snake venom toxins to therapeutics-cardiovascular examples, Toxicon 59 (2012) 497-506.

[69] King GF, Escoubas P, Nicholson GM, Peptide toxins that selectively target insect Navand Cav channels, Channels 2 (2008) 100-116.

[70] Vassilevski AA, Kozlov SA, Grishin EV, Molecular diversity of spider venom, Biochemistry (Mosc). 74 (2009) 1505-1534. 
[71] Liao Y, Anttonen AK, Liukkonen E, Gaily E, Maljevic S, Schubert S, et al., SCN2A mutation associated with neonatal epilepsy, late-onset episodic ataxia, myoclonus, and pain, Neurology 75 (2010) 14541458.

[72] Quintero-Hernandez V, Jimenez-Vargas JM, Gurrola GB, Valdivia HH, Possani LD, Scorpion venom components that affect ion-channels function, Toxicon 76 (2013) 328-342.

[73] Walker AA, Mayhew ML, Jin J, Herzig V, Undheim EAB, Sombke A, et al., The assassin bug Pristhesancus plagipennis produces two distinct venoms in separate gland lumens, Nat Commun 9 (2018) 755.

[74] Robinson SD, Mueller A, Clayton D, Starobova H, Hamilton BR, Payne RJ, et al., A comprehensive portrait of the venom of the giant red bull ant, Myrmecia gulosa, reveals a hyperdiverse hymenopteran toxin gene family, Sci Adv 4 (2018) eaau4640.

[75] Teichert R, Olivera B, Mcintosh J, Bulaj G, Horvath M. The molecular diversity of Conoidean venom peptides and their targets: from basic research to therapeutic applications. In: King GF, editor. Venoms to Drugs: Venoms as a Source for the Development of Human Therapeutics. London, UK: Royal Society of Chemistry, 2015. p. 163-203.

[76] Rodríguez de la Vega RC, Corzo G, Possani LD. Scorpion venoms as a platform for drug development. In: King GF, editor. Venoms to Drugs: Venoms as a Source for the Development of Human Therapeutics. London, UK: Royal Society of Chemistry, 2015. p. 204-220.

[77] Touchard A, Aili SR, Fox EG, Escoubas P, Orivel J, Nicholson GM, et al., The biochemical toxin arsenal from ant venoms, Toxins 8 (2016) 30.

[78] Undheim EA, Jenner RA, King GF, Centipede venoms as a source of drug leads, Expert Opin Drug Discov 11 (2016) 1139-1149.

[79] Saez NJ, Herzig V, Versatile spider venom peptides and their medical and agricultural applications, Toxicon 158 (2019) 109-126.

[80] Olivera BM, Hillyard DR, Marsh M, Yoshikami D, Combinatorial peptide libraries in drug design: lessons from venomous cone snails, Trends Biotechnol 13 (1995) 422-426. 
[81] Sollod BL, Wilson D, Zhaxybayeva O, Gogarten JP, Drinkwater R, King GF, Were arachnids the first to use combinatorial peptide libraries?, Peptides 26 (2005) 131-139.

[82] Pineda S, Chin Y, Undheim E, Senff S, Mobli M, Dauly C, et al., Structural venomics reveals evolution of a complex venom by duplication and diversification of an ancient peptide-encoding gene, Proc Natl Acad Sci USA (2020) in press.

[83] Vetter I, Davis JL, Rash LD, Anangi R, Mobli M, Alewood PF, et al., Venomics: a new paradigm for natural products-based drug discovery, Amino Acids 40 (2011) 15-28.

[84] McGonigle P, Peptide therapeutics for CNS indications, Biochem Pharmacol 83 (2012) 559-566.

[85] Morimoto BH, Therapeutic peptides for CNS indications: Progress and challenges, Bioorg Med Chem 26 (2018) 2859-2862.

[86] Klint JK, Senff S, Saez NJ, Seshadri R, Lau HY, Bende NS, et al., Production of recombinant disulfiderich venom peptides for structural and functional analysis via expression in the periplasm of $E$. coli, PLoS One 8 (2013) e63865.

[87] Werbitzky O, Giraud M. Manufacturing of venom- derived therapeutic peptides. In: King GF, editor. Venoms to Drugs: Venoms as a Source for the Development of Human Therapeutics. London, UK: Royal Society of Chemistry, 2015. p. 290-305.

[88] Malins LR, Payne RJ, Recent extensions to native chemical ligation for the chemical synthesis of peptides and proteins, Curr Opin Chem Biol 22 (2014) 70-78.

[89] Gentilucci L, Tosi P, Bauer A, De Marco R, Modern tools for the chemical ligation and synthesis of modified peptides and proteins, Future Med Chem 8 (2016) 2287-2304.

[90] Turchetto J, Sequeira AF, Ramond L, Peysson F, Bras JL, Saez NJ, et al., High-throughput expression of animal venom toxins in Escherichia coli to generate a large library of oxidized disulphidereticulated peptides for drug discovery, Microb Cell Fact 16 (2017) 6.

[91] Hay M, Thomas DW, Craighead JL, Economides C, Rosenthal J, Clinical development success rates for investigational drugs, Nat Biotechnol 32 (2014) 40-51. 
[92] Lozano-Fernandez J, Carton R, Tanner AR, Puttick MN, Blaxter M, Vinther J, et al., A molecular palaeobiological exploration of arthropod terrestrialization, Philos. Trans. R. Soc. Lond., B, Biol. Sci. 371 (2016) 20150133.

[93] World Spider Catalog. Available online at http://wsc.nmbe.ch, version 20.5, accessed on May 6, 2020. Natural History Museum Bern, 2020.

[94] Rash LD, Hodgson WC, Pharmacology and biochemistry of spider venoms, Toxicon 40 (2002) 225254.

[95] Kuhn-Nentwig L, Stocklin R, Nentwig W, Venom composition and strategies in spiders: Is everything possible?, Adv Insect Phys 40 (2011) 1-86.

[96] Pallaghy PK, Nielsen KJ, Craik DJ, Norton RS, A common structural motif incorporating a cystine knot and a triple-stranded $\beta$-sheet in toxic and inhibitory polypeptides, Protein Sci 3 (1994) 1833-1839.

[97] Norton RS, Pallaghy PK, The cystine knot structure of ion channel toxins and related polypeptides, Toxicon 36 (1998) 1573-1583.

[98] King GF, Tedford HW, Maggio F, Structure and function of insecticidal neurotoxins from Australian funnel-web spiders., J Toxicol Toxin Rev 21 (2002) 361-389.

[99] Herzig V, King GF, The cystine knot is responsible for the exceptional stability of the insecticidal spider toxin $\omega$-hexatoxin-Hv1a, Toxins 7 (2015) 4366-4380.

[100] Catterall WA, From ionic currents to molecular mechanisms: the structure and function of voltagegated sodium channels, Neuron 26 (2000) 13-25.

[101] Beneski DA, Catterall WA, Covalent labeling of protein components of the sodium channel with a photoactivable derivative of scorpion toxin, Proc Natl Acad Sci USA 77 (1980) 639-643.

[102] Catterall WA, Goldin AL, Waxman SG, International Union of pharmacology. XLVII. Nomenclature and structure-function relationships of voltage-gated sodium channels, Pharmacol Rev 57 (2005) 397-409. 
[103] Klint JK, Senff S, Rupasinghe DB, Er SY, Herzig V, Nicholson GM, et al., Spider-venom peptides that target voltage-gated sodium channels: pharmacological tools and potential therapeutic leads, Toxicon 60 (2012) 478-491.

[104] Pan X, Li Z, Huang X, Huang G, Gao S, Shen H, et al., Molecular basis for pore blockade of human $\mathrm{Na}^{+}$ channel Nav1.2 by the $\mu$-conotoxin KIIIA, Science 363 (2019) 1309-1313.

[105] Shen H, Li Z, Jiang Y, Pan X, Wu J, Cristofori-Armstrong B, et al., Structural basis for the modulation of voltage-gated sodium channels by animal toxins, Science 362 (2018) eaau2596

[106] Xu H, Li T, Rohou A, Arthur CP, Tzakoniati F, Wong E, et al., Structural basis of Nav1.7 inhibition by a gating-modifier spider toxin, Cell 176 (2019) 702-715 e714.

[107] Shen H, Liu D, Wu K, Lei J, Yan N, Structures of human Nav1.7 channel in complex with auxiliary subunits and animal toxins, Science 363 (2019) 1303-1308.

[108] Dravet C, Oguni H, Dravet syndrome (severe myoclonic epilepsy in infancy), Handb Clin Neurol 111 (2013) 627-633.

[109] Ogiwara I, Miyamoto H, Morita N, Atapour N, Mazaki E, Inoue I, et al., Nav1.1 localizes to axons of parvalbumin-positive inhibitory interneurons: a circuit basis for epileptic seizures in mice carrying an Scn1a gene mutation, J. Neurosci. 27 (2007) 5903-5914.

[110] Liautard C, Scalmani P, Carriero G, de Curtis M, Franceschetti S, Mantegazza M, Hippocampal hyperexcitability and specific epileptiform activity in a mouse model of Dravet syndrome, Epilepsia 54 (2013) 1251-1261.

[111] Osteen JD, Herzig V, Gilchrist J, Emrick JJ, Zhang C, Wang X, et al., Selective spider toxins reveal a role for the Nav1.1 channel in mechanical pain, Nature 534 (2016) 494-499.

[112] Heron SE, Crossland KM, Andermann E, Phillips HA, Hall AJ, Bleasel A, et al., Sodium-channel defects in benign familial neonatal-infantile seizures, Lancet. 360 (2002) 851-852.

[113] Berkovic SF, Heron SE, Giordano L, Marini C, Guerrini R, Kaplan RE, et al., Benign familial neonatalinfantile seizures: characterization of a new sodium channelopathy, Ann Neurol 55 (2004) 550-557. 
[114] Wolff M, Johannesen KM, Hedrich UBS, Masnada S, Rubboli G, Gardella E, et al., Genetic and phenotypic heterogeneity suggest therapeutic implications in SCN2A-related disorders, Brain 140 (2017) 1316-1336.

[115] Sanders SJ, Campbell AJ, Cottrell JR, Moller RS, Wagner FF, Auldridge AL, et al., Progress in understanding and treating SCN2A-mediated disorders, Trends Neurosci 41 (2018) 442-456.

[116] de Kovel CG, Meisler MH, Brilstra EH, van Berkestijn FM, van 't Slot R, van Lieshout S, et al., Characterization of a de novo SCN8A mutation in a patient with epileptic encephalopathy, Epilepsy Res 108 (2014) 1511-1518.

[117] Gardella E, Becker F, Moller RS, Schubert J, Lemke JR, Larsen LH, et al., Benign infantile seizures and paroxysmal dyskinesia caused by an SCN8A mutation, Ann Neurol 79 (2016) 428-436.

[118] Hu W, Tian C, Li T, Yang M, Hou H, Shu Y, Distinct contributions of Nav1.6 and Nav1.2 in action potential initiation and backpropagation, Nat Neurosci 12 (2009) 996-1002.

[119] Tian C, Wang K, Ke W, Guo H, Shu Y, Molecular identity of axonal sodium channels in human cortical pyramidal cells, Front Cell Neurosci 8 (2014) 297.

[120] Bosmans F, Rash L, Zhu S, Diochot S, Lazdunski M, Escoubas P, et al., Four novel tarantula toxins as selective modulators of voltage-gated sodium channel subtypes, Mol Pharmacol 69 (2006) 419-429.

[121] Schmalhofer WA, Calhoun J, Burrows R, Bailey T, Kohler MG, Weinglass AB, et al., ProTx-II, a selective inhibitor of Nav1.7 sodium channels, blocks action potential propagation in nociceptors, Mol Pharmacol 74 (2008) 1476-1484.

[122] Agwa AJ, Peigneur S, Chow CY, Lawrence N, Craik DJ, Tytgat J, et al., Gating modifier toxins isolated from spider venom: Modulation of voltage-gated sodium channels and the role of lipid membranes, J Biol Chem 293 (2018) 9041-9052.

[123] Ye M, Yang J, Tian C, Zhu Q, Yin L, Jiang S, et al., Differential roles of Nav1.2 and Nav1.6 in regulating neuronal excitability at febrile temperature and distinct contributions to febrile seizures, Sci Rep 8 (2018) 753. 
[124] Corzo G, Sabo JK, Bosmans F, Billen B, Villegas E, Tytgat J, et al., Solution structure and alanine scan of a spider toxin that affects the activation of mammalian voltage-gated sodium channels, J. Biol. Chem. 282 (2007) 4643-4652.

[125] Biggin PC, Roosild T, Chloe S, Potassium channel structure: domain by domain, Curr Opin Struct Biol 10 (2000) 456-461.

[126] Doyle DA, Cabral JM, Pfuetzner RA, Kuo A, Gulbis JM, Cohen SL, et al., The structure of the potassium channel: molecular basis of $\mathrm{K}^{+}$conduction and selectivity, Science 280 (1998) 69-77.

[127] MacKinnon R, Miller C, Mutant potassium channels with altered binding of charybdotoxin, a poreblocking peptide inhibitor, Science 245 (1989) 1382-1385.

[128] Hartmann HA, Kirsch GE, Drewe JA, Joho RH, Brown AM, Exchange of conduction pathways between two related K+ channels, Science 251 (1991) 942-944.

[129] Yool AJ, Schwarz TL, Alteration of ionic selectivity of a $\mathrm{K}^{+}$channel by mutation of the $\mathrm{H} 5$ region, Nature 349 (1991) 700-704.

[130] Goldstein SA, Pheasant DJ, Miller C, The charybdotoxin receptor of a Shaker K ${ }^{+}$channel: peptide and channel residues mediating molecular recognition, Neuron 12 (1994) 1377-1388.

[131] MacKinnon R, Determination of the subunit stoichiometry of a voltage-activated potassium channel, Nature 350 (1991) 232-235.

[132] MacKinnon R, Aldrich RW, Lee AW, Functional stoichiometry of shaker potassium channel inactivation, Science 262 (1993) 757-759.

[133] Hildago P, MacKinnon R, Revealing the architecture of a $\mathrm{K}^{+}$channel pore through mutant cycles with a peptide inhibitor, Science 268 (1995) 307-310.

[134] Robitaille R, Garcia M, Kaczorowski GJ, Charlton MP, Functional colocalization of calcium and calcium-gated potassium channels in control of transmitter release, Neuron 11 (1993) 645-655. 
[135] Browne DL, Gancher ST, Nutt JG, Brunt ER, Smith EA, Kramer P, et al., Episodic ataxia/myokymia syndrome is associated with point mutations in the human potassium channel gene, KCNA1, Nat Genet 8 (1994) 136-140.

[136] Muona M, Berkovic SF, Dibbens LM, Oliver KL, Maljevic S, Bayly MA, et al., A recurrent de novo mutation in KCNC1 causes progressive myoclonus epilepsy, Nat Genet 47 (2015) 39-46.

[137] Singh NA, Charlier C, Stauffer D, DuPont BR, Leach RJ, Melis R, et al., A novel potassium channel gene, KCNQ2, is mutated in an inherited epilepsy of newborns, Nat Genet 18 (1998) 25-29.

[138] Parrini E, Marini C, Mei D, Galuppi A, Cellini E, Pucatti D, et al., Diagnostic targeted resequencing in 349 patients with drug-resistant pediatric epilepsies identifies causative mutations in 30 different genes, Hum Mutat 38 (2017) 216-225.

[139] Kortum F, Caputo V, Bauer CK, Stella L, Ciolfi A, Alawi M, et al., Mutations in KCNH1 and ATP6V1B2 cause Zimmermann-Laband syndrome, Nat Genet 47 (2015) 661-667.

[140] Shen JJ, Two cases of Temple-Baraitser syndrome: natural history and further delineation of the clinical and radiological phenotypes, Clin Dysmorphol 24 (2015) 55-60.

[141] Vandenberg JI, Perry MD, Perrin MJ, Mann SA, Ke Y, Hill AP, hERG K+ channels: structure, function, and clinical significance, Physiol Rev 92 (2012) 1393-1478.

[142] Caterall CA, Voltage-gated calcium channels, Cold Spring Harb Perspect Biol 3 (2011) a003947.

[143] Bers DM, Cardiac excitation-contraction coupling, Nature 415 (2002) 198-205.

[144] Flavell SW, Greenberg ME, Signaling mechanisms linking neuronal activity to gene expression and plasticity of the nervous system, Annu Revi Neurosci 31 (2008) 563-590.

[145] Yang SN, Berggren PO, The role of voltage-gated calcium channels in pancreatic $\beta$-cell physiology and pathophysiology, Endocrine Rev 27 (2006) 621-676.

[146] Sousa SR, Vetter I, Lewis RJ, Venom peptides as a rich source of Cav2.2 channel blockers, Toxins 5 (2013) 286-314.

[147] Currie KPM, G protein inhibition of Cav2 calcium channels Channels 4 (2010) 497-509. 
[148] Candelas M, Reynders A, Arango-Lievano M, Neumayer C, Fruquière A, Demes E, et al., Cav3.2 T-type calcium channels shape electrical firing in mouse lamina II neurons, Sci Rep 9 (2019) 3112.

[149] Zamponi G, Targeting voltage-gated calcium channels in neurological and psychiatric diseases, Nat Rev Drug Discov 15 (2016).

[150] Dolphin AC, Voltage-gated calcium channels and their auxiliary subunits: physiology and pathophysiology and pharmacology, J Physiol 594 (2016) 5369-5390.

[151] Zhao Y, Huang G, Wu Q, Wu K, Li R, Lei J, et al., Cryo-EM stucture of apo and antagonist-bound human Cav3.1, Nature 576 (2019) 492-497.

[152] Olivera BM, Miljanich GP, Ramachandran J, Adams ME, Calcium channel diversity and neurotransmitter release: the $\omega$-conotoxins and $\omega$-agatoxins, Annu Rev Biochem 63 (1994) 823-867.

[153] Newcomb R, Szoke B, Palma A, Wang G, Chen X, Hopkins W, et al., Selective peptide anatagonist of the class E calcium channel from the venom of the tarantula Hysterocrates gigas, Biochemistry 37 (1998) 15353-15362.

[154] Ellinor PT, Zhang J-F, Horne WA, Tsien RW, Structural determinants of the blockade of N-type calcium channels by a peptide neurotoxin, Nature 372 (1994) 272-275.

[155] Damaj L, Lupien-Meilleur A, Lortie A, Riou É, Ospina LH, Gagnon L, et al., CACNA1A haploinsufficiency causes cognitive impairment, autism and epileptic encephalopathy with mild cerebellar symptoms, Eur J Hum Genet 23 (2015) 1505-1512.

[156] Caddick SJ, Wang C, Fletcher CF, Jenkins NA, Copeland NG, Hosford DA, Excitatory but not inhibitory synaptic transmission is reduced in lethargic $\left(\right.$ Cacnb $\left.4^{\mathrm{lh}}\right)$ and tottering $\left(\right.$ Cacna1 $\left.{ }^{\mathrm{tg}}\right)$ mouse thalami, J Neurophysiol 81 (1999) 2066-2074.

[157] Ayata C, Shimizu-Sasamata M, Lo EH, Noebels JL, Moskowitz MA, Impaired neurotransmitter release and elevated threshold for cortical spreading depression in mice with mutations in the $\alpha 1 \mathrm{~A}$ subunit of P/Q type calcium channels, Neuroscience 95 (2000) 639-645. 
[158] Escayg A, De Waard M, Lee DD, Bichet D, Wolf P, Mayer T, et al., Coding and noncoding variation of the human calcium-channel $\beta 4$-subunit gene CACNB4 in patients with idiopathic generalized epilepsy and episodic ataxia, Am J Hum Genet 66 (2000) 1531-1539.

[159] Heron SE, Khosravani H, Varela D, Bladen C, Williams TC, Newman MR, et al., Extended spectrum of idiopathic generalized epilepsies associated with CACNA1H functional variants, Ann Neurol 62 (2007) 560-568.

[160] Perez-Reyes E, Molecular physiology of low-voltage-activated t-type calcium channels, Physiol Rev 83 (2003) 117-161.

[161] Becker AJ, Pitsch J, Sochivko D, Opitz T, Staniek M, Chen CC, et al., Transcriptional upregulation of Cav3.2 mediates epileptogenesis in the pilocarpine model of epilepsy, J Neurosci 28 (2008) 1334113353.

[162] Ramirez D, Gonzalez W, Fissore RA, Carvacho I, Conotoxins as tools to understand the physiological function of voltage-gated calcium (Cav) channels, Mar Drugs 15 (2017) 313.

[163] Smith JJ, Lau CHY, Herzig V, Ikonomopoulou MP, Rash LD, King GF. Therapeutic applications of spidervenom peptides. In: King GF, editor. Venoms to Drugs: Venoms as a Source for the Development of Human Therapeutics. London, UK: Royal Society of Chemistry, 2015. p. 221-244.

[164] Vieira LB, Kushmerick C, Hildebrand ME, Garcia E, Stea A, Cordeiro MN, et al., Inhibition of high voltage-activated calcium channels by spider toxin PnTx3-6, J Pharmacol Exp Ther 314 (2005) 13701377.

[165] Tonello R, Fusi C, Materazzi S, Marone IM, De Logu F, Benemei S, et al., The peptide Pha1ß, from spider venom, acts as a TRPA1 channel antagonist with antinociceptive effects in mice, $\mathrm{Br} \mathrm{J}$ Pharmacol 174 (2017) 57-69.

[166] Silva RBM, Greggio S, Venturin GT, da Costa JC, Gomez MV, Campos MM, Beneficial effects of the calcium channel blocker CTK 01512-2 in a mouse model of multiple sclerosis, Mol Neurobiol 55 (2018) 9307-9327. 
[167] Maciel IS, Azevedo VM, Pereira TC, Bogo MR, Souza AH, Gomez MV, et al., The spinal inhibition of $\mathrm{N}$-type voltage-gated calcium channels selectively prevents scratching behavior in mice, Neuroscience 277 (2014) 794-805.

[168] Nicoletti NF, Erig TC, Zanin RF, Roxo MR, Ferreira NP, Gomez MV, et al., Pre-clinical evaluation of voltage-gated calcium channel blockers derived from the spider $P$. nigriventer in glioma progression, Toxicon 129 (2017) 58-67.

[169] Sine SM, Engel AG, Recent advances in Cys-loop receptor structure and function, Nature 440 (2006) 448-455.

[170] Wolstenholme AJ, Glutamate-gated chloride channels, J Biol Chem 287 (2012) 40232-40238.

[171] Keramidas A, Moorhouse AJ, Schofield PR, Barry PH, Ligand-gated ion channels: mechanisms underlying ion selectivity, Prog Biophys Mol Biol 86 (2004) 161-204.

[172] Chua $\mathrm{HC}$, Chebib $\mathrm{M}, \mathrm{GABA}_{\mathrm{A}}$ receptors and the diversity in their structure and pharmacology, Adv Pharmacol 79 (2017) 1-34.

[173] Albuquerque EX, Pereira EF, Alkondon M, Rogers SW, Mammalian nicotinic acetylcholine receptors: from structure to function, Physiol Rev 89 (2009) 73-120.

[174] Brejc K, van Dijk WJ, Klaassen RV, Schuurmans M, van Der Oost J, Smit AB, et al., Crystal structure of an ACh-binding protein reveals the ligand-binding domain of nicotinic receptors, Nature 411 (2001) 269-276.

[175] Scott S, Aricescu AR, A structural perspective on $\mathrm{GABA}_{A}$ receptor pharmacology, Curr Opin Struct Biol 54 (2019) 189-197.

[176] Dingledine R, Borges K, Bowie D, Traynelis SF, The glutamate receptor ion channels, Pharmacol Rev 51 (1999) 7-61.

[177] Traynelis SF, Wollmuth LP, McBain CJ, Menniti FS, Vance KM, Ogden KK, et al., Glutamate receptor ion channels: structure, regulation, and function, Pharmacol Rev 62 (2010) 405-496. 
[178] Sobolevsky Al, Rosconi MP, Gouaux E, X-ray structure, symmetry and mechanism of an AMPAsubtype glutamate receptor, Nature 462 (2009) 745-756.

[179] Vyklicky V, Korinek M, Smejkalova T, Balik A, Krausova B, Kaniakova M, et al., Structure, function, and pharmacology of NMDA receptor channels, Physiol Res 63 Suppl 1 (2014) S191-5203.

[180] Mansoor SE, Lu W, Oosterheert W, Shekhar M, Tajkhorshid E, Gouaux E, X-ray structures define human $\mathrm{P} 2 \mathrm{X}_{3}$ receptor gating cycle and antagonist action, Nature 538 (2016) 66-71.

[181] Kang JQ, Macdonald RL, Molecular pathogenic basis for GABRG2 mutations associated with a spectrum of epilepsy syndromes, from generalized absence epilepsy to Dravet syndrome, JAMA Neurol 73 (2016) 1009-1016.

[182] Baulac S, Huberfeld G, Gourfinkel-An I, Mitropoulou G, Beranger A, Prud'homme JF, et al., First genetic evidence of $\mathrm{GABA}_{\mathrm{A}}$ receptor dysfunction in epilepsy: a mutation in the gamma2-subunit gene, Nat Genet 28 (2001) 46-48.

[183] Cossette P, Liu L, Brisebois K, Dong H, Lortie A, Vanasse M, et al., Mutation of GABRA1 in an autosomal dominant form of juvenile myoclonic epilepsy, Nat Genet 31 (2002) 184-189.

[184] Epi4K Consortium, Allen AS, Berkovic SF, Cossette P, Delanty N, Dlugos D, et al., De novo mutations in epileptic encephalopathies, Nature 501 (2013) 217-221.

[185] De Fusco M, Becchetti A, Patrignani A, Annesi G, Gambardella A, Quattrone A, et al., The nicotinic receptor $\beta 2$ subunit is mutant in nocturnal frontal lobe epilepsy, Nat Genet 26 (2000) 275-276.

[186] Bertrand D, Picard F, Le Hellard S, Weiland S, Favre I, Phillips H, et al., How mutations in the nAChRs can cause ADNFLE epilepsy, Epilepsia 43 Suppl 5 (2002) 112-122.

[187] Harpsoe K, Ahring PK, Christensen JK, Jensen ML, Peters D, Balle T, Unraveling the high- and lowsensitivity agonist responses of nicotinic acetylcholine receptors, J Neurosci 31 (2011) 10759-10766.

[188] Indurthi DC, Qudah T, Liao VW, Ahring PK, Lewis TM, Balle T, et al., Revisiting autosomal dominant nocturnal frontal lobe epilepsy (ADNFLE) mutations in the nicotinic acetylcholine receptor reveal an increase in efficacy regardless of stochiometry, Pharmacol Res 139 (2019) 215-227. 
[189] Salpietro V, Dixon CL, Guo H, Bello OD, Vandrovcova J, Efthymiou S, et al., AMPA receptor GluA2 subunit defects are a cause of neurodevelopmental disorders, Nat Commun 10 (2019) 3094.

[190] XiangWei W, Jiang Y, Yuan H, De novo mutations and rare variants occurring in NMDA receptors, Curr Opin Physiol 2 (2018) 27-35.

[191] Yuan H, Hansen KB, Zhang J, Pierson TM, Markello TC, Fajardo KV, et al., Functional analysis of a de novo GRIN2A missense mutation associated with early-onset epileptic encephalopathy, Nat Commun 5 (2014) 3251.

[192] Endele S, Rosenberger G, Geider K, Popp B, Tamer C, Stefanova I, et al., Mutations in GRIN2A and GRIN2B encoding regulatory subunits of NMDA receptors cause variable neurodevelopmental phenotypes, Nat Genet 42 (2010) 1021-1026.

[193] Li D, Yuan H, Ortiz-Gonzalez XR, Marsh ED, Tian L, McCormick EM, et al., GRIN2D recurrent de novo dominant mutation causes a severe epileptic encephalopathy treatable with NMDA receptor channel blockers, Am J Hum Genet 99 (2016) 802-816.

[194] Palma E, Ruffolo G, Cifelli P, Roseti C, Vliet EAV, Aronica E, Modulation of GABA $A_{A}$ receptors in the treatment of epilepsy, Curr Pharm Des 23 (2017) 5563-5568.

[195] Anderson LL, Absalom NL, Abelev SV, Low IK, Doohan PT, Martin L, et al., Coadministered cannabidiol and clobazam: preclinical evidence for both pharmacodynamic and pharmacokinetic interactions, Epilepsia 60 (2019) 2224-2234.

[196] Klein P, Tolbert D, Gidal BE, Drug-drug interactions and pharmacodynamics of concomitant clobazam and cannabidiol or stiripentol in refractory seizures, Epilepsy Behav 99 (2019) 106459.

[197] Rosso JP, Schwarz JR, Diaz-Bustamante M, Ceard B, Gutierrez JM, Kneussel M, et al., MmTX1 and MmTX2 from coral snake venom potently modulate $\mathrm{GABA}_{\mathrm{A}}$ receptor activity, Proc Natl Acad Sci USA 112 (2015) E891-E900.

[198] Butler KM, Moody OA, Schuler E, Coryell J, Alexander JJ, Jenkins A, et al., De novo variants in GABRA2 and GABRA5 alter receptor function and contribute to early-onset epilepsy, Brain 141 (2018) 23922405. 
[199] Itier V, Bertrand D, Mutations of the neuronal nicotinic acetylcholine receptors and their association with ADNFLE, Neurophysiol Clin 32 (2002) 99-107.

[200] Zheng C, Yang K, Liu Q, Wang MY, Shen J, Valles AS, et al., The anticonvulsive drug lamotrigine blocks neuronal $\alpha 4 \beta 2$ nicotinic acetylcholine receptors, J Pharmacol Exp Ther 335 (2010) 401-408.

[201] Chopra DA, Shah AB, Vadhariya AH, Painter JT, The risk of varenicline-induced seizure among those who have attempted to quit smoking using pharmacotherapy, Epilepsy Behav 97 (2019) 169-173.

[202] Bertrand D, Terry AV, Jr., The wonderland of neuronal nicotinic acetylcholine receptors, Biochem Pharmacol 151 (2018) 214-225.

[203] Pohanka M, $\alpha 7$ nicotinic acetylcholine receptor is a target in pharmacology and toxicology, Int J Mol Sci 13 (2012) 2219-2238.

[204] Dutertre S, Nicke A, Tsetlin VI, Nicotinic acetylcholine receptor inhibitors derived from snake and snail venoms, Neuropharmacology 127 (2017) 196-223.

[205] Mclntosh JM, Santos AD, Olivera BM, Conus peptides targeted to specific nicotinic acetylcholine receptor subtypes, Annu Rev Biochem 68 (1999) 59-88.

[206] Abraham N, Lewis RJ, Neuronal nicotinic acetylcholine receptor modulators from cone snails, Mar Drugs 16 (2018) 208.

[207] Kasheverov IE, Oparin PB, Zhmak MN, Egorova NS, Ivanov IA, Gigolaev AM, et al., Scorpion toxins interact with nicotinic acetylcholine receptors, FEBS Lett 593 (2019) 2779-2789.

[208] Kini RM, Toxins for decoding interface selectivity in nicotinic acetylcholine receptors, Biochem J 476 (2019) 1515-1520.

[209] Windley MJ, Vetter I, Lewis RJ, Nicholson GM, Lethal effects of an insecticidal spider venom peptide involve positive allosteric modulation of insect nicotinic acetylcholine receptors, Neuropharmacology 127 (2017) 224-242.

[210] Olivera BM, Quik M, Vincler M, Mclntosh JM, Subtype-selective conopeptides targeted to nicotinic receptors: concerted discovery and biomedical applications, Channels 2 (2008) 143-152. 
[211] Rogawski MA, Revisiting AMPA receptors as an antiepileptic drug target, Epilepsy Curr 11 (2011) 5663.

[212] Lee WL, Hablitz JJ, Involvement of non-NMDA receptors in picrotoxin-induced epileptiform activity in the hippocampus, Neurosci Lett 107 (1989) 129-134.

[213] Perreault P, Avoli M, Physiology and pharmacology of epileptiform activity induced by 4aminopyridine in rat hippocampal slices, J Neurophysiol 65 (1991) 771-785.

[214] Hwa GG, Avoli M, The involvement of excitatory amino acids in neocortical epileptogenesis: NMDA and non-NMDA receptors, Exp Brain Res 86 (1991) 248-256.

[215] Pina-Garza JE, Rosenfeld W, Saeki K, Villanueva V, Yoshinaga H, Patten A, et al., Efficacy and safety of adjunctive perampanel in adolescent patients with epilepsy: post hoc analysis of six randomized studies, Epilepsy Behav 104 (2020) 106876.

[216] Filchakova O, Spider toxins targeting ligand-gated ion channels, Toxin Rev (2019) doi: 10.1080/15569543.15562019.11579230.

[217] Salamoni SD, da Costa JC, Palma MS, Konno K, Nihei K, Azambuja NA, et al., The antiepileptic activity of JSTX-3 is mediated by N-methyl-D-aspartate receptors in human hippocampal neurons, Neuroreport 16 (2005) 1869-1873.

[218] Gomez MV, Kalapothakis E, Guatimosim C, Prado MA, Phoneutria nigriventer venom: a cocktail of toxins that affect ion channels, Cell Mol Neurobiol 22 (2002) 579-588.

[219] Santos R, Ursu O, Gaulton A, Bento AP, Donadi RS, Bologa CG, et al., A comprehensive map of molecular drug targets, Nat Rev Drug Discov 16 (2017) 19-34.

[220] Wulff H, Christophersen P, Colussi P, Chandy KG, Yarov-Yarovoy V, Antibodies and venom peptides: new modalities for ion channels, Nat Rev Drug Discov 18 (2019) 339-357.

[221] Pineda SS, Undheim EA, Rupasinghe DB, Ikonomopoulou MP, King GF, Spider venomics: implications for drug discovery, Future Med Chem 6 (2014) 1699-1714.

[222] Calvete JJ, Venomics: integrative venom proteomics and beyond, Biochem J 474 (2017) 611-634. 
[223] Walker AA, Robinson SD, Jones A, Hamilton BF, Undheim EAB, King GF, Deadly proteomes: the central role of proteomics in dissecting the chemical arsenal of animal venoms, Proteomics (2020) in press.

[224] Vetter I, Hodgson WC, Adams DJ, Mclntyre P. Venoms-based drug discovery: bioassays, electrophysiology, high-throughput screens and target identification. In: King GF, editor. Venoms to Drugs: Venoms as a Source for the Development of Human Therapeutics. London, UK: Royal Society of Chemistry, 2015. p. 97-128.

[225] Prashanth JR, Hasaballah N, Vetter I, Pharmacological screening technologies for venom peptide discovery, Neuropharmacology 127 (2017) 4-19.

[226] Fletcher JI, Smith R, O'Donoghue SI, Nilges M, Connor M, Howden ME, et al., The structure of a novel insecticidal neurotoxin, $\omega$-atracotoxin-HV1, from the venom of an Australian funnel web spider, Nat Struct Biol 4 (1997) 559-566.

[227] Peng K, Shu Q, Liu Z, Liang S, Function and solution structure of huwentoxin-IV, a potent neuronal tetrodotoxin (TTX)-sensitive sodium channel antagonist from Chinese bird spider Selenocosmia huwena, J Biol Chem 277 (2002) 47564-47571.

[228] Wang X, Connor M, Smith R, Maciejewski MW, Howden ME, Nicholson GM, et al., Discovery and characterization of a family of insecticidal neurotoxins with a rare vicinal disulfide bridge, Nat Struct Biol 7 (2000) 505-513.

[229] Rosengren KJ, Wilson D, Daly NL, Alewood PF, Craik DJ, Solution structures of the cis- and transPro30 isomers of a novel 38-residue toxin from the venom of Hadronyche infensa sp. that contains a cystine-knot motif within its four disulfide bonds, Biochemistry 41 (2002) 3294-3301.

[230] Takahashi H, Kim JI, Min HJ, Sato K, Swartz KJ, Shimada I, Solution structure of hanatoxin1, a gating modifier of voltage-dependent $\mathrm{K}^{+}$channels: common surface features of gating modifier toxins, J Mol Biol 297 (2000) 771-780. 
[231] Fletcher JI, Chapman BE, Mackay JP, Howden ME, King GF, The structure of versutoxin ( $\delta$ atracotoxin-Hv1) provides insights into the binding of site 3 neurotoxins to the voltage-gated sodium channel, Structure 5 (1997) 1525-1535.

[232] Payandeh J, Scheuer T, Zheng N, Catterall WA, The crystal structure of a voltage-gated sodium channel, Nature 475 (2011) 353-358.

[233] Shen H, Zhou Q, Pan X, Li Z, Wu J, Yan N, Structure of a eukaryotic voltage-gated sodium channel at near-atomic resolution, Science 355 (2017) eaal4326.

[234] Laverty D, Desai R, Uchanski T, Masiulis S, Stec WJ, Malinauskas T, et al., Cryo-EM structure of the human $\alpha 1 \beta 3 \gamma 2 \mathrm{GABA}_{\mathrm{A}}$ receptor in a lipid bilayer, Nature 565 (2019) 516-520.

[235] Twomey EC, Yelshanskaya MV, Grassucci RA, Frank J, Sobolevsky Al, Channel opening and gating mechanism in AMPA-subtype glutamate receptors, Nature 549 (2017) 60-65.

[236] McCarthy AE, Yoshioka C, Mansoor SE, Full-length $\mathrm{P} 2 \mathrm{X}_{7}$ structures reveal how palmitoylation prevents channel desensitization, Cell 179 (2019) 659-670.

[237] Claes L, Del-Favero J, Ceulemans B, Lagae L, Van Broeckhoven C, De Jonghe P, De novo mutations in the sodium-channel gene SCN1A cause severe myoclonic epilepsy of infancy, Am J Hum Genet 68 (2001) 1327-1332.

[238] Escayg A, Heils A, MacDonald BT, Haug K, Sander T, Meisler MH, A novel SCN1A mutation associated with generalized epilepsy with febrile seizures plus-and prevalence of variants in patients with epilepsy, Am J Hum Genet 68 (2001) 866-873.

[239] Harkin LA, McMahon JM, Iona X, Dibbens L, Pelekanos JT, Zuberi SM, et al., The spectrum of SCN1Arelated infantile epileptic encephalopathies, Brain. 130 (2007) 843-852.

[240] Patino GA, Claes LR, Lopez-Santiago LF, Slat EA, Dondeti RS, Chen C, et al., A functional null mutation of SCN1B in a patient with Dravet syndrome, J Neurosci 29 (2009) 10764-10778.

[241] Scheffer IE, Harkin LA, Grinton BE, Dibbens LM, Turner SJ, Zielinski MA, et al., Temporal lobe epilepsy and GEFS+ phenotypes associated with SCN1B mutations, Brain 130 (2007) 100-109. 
[242] Wallace RH, Wang DW, Singh R, Scheffer IE, George AL, Jr., Phillips HA, et al., Febrile seizures and generalized epilepsy associated with a mutation in the $\mathrm{Na}^{+}$channel $\beta 1$ subunit gene $S C N 1 B, N a t$ Genet 19 (1998) 366-370.

[243] Shi X, Yasumoto S, Nakagawa E, Fukasawa T, Uchiya S, Hirose S, Missense mutation of the sodium channel gene SCN2A causes Dravet syndrome, Brain Dev 31 (2009) 758-762.

[244] Verdura E, Fons C, Schluter A, Ruiz M, Fourcade S, Casasnovas C, et al., Complete loss of KCNA1 activity causes neonatal epileptic encephalopathy and dyskinesia, J Med Genet 57 (2020) 132-137.

[245] Syrbe S, Hedrich UBS, Riesch E, Djemie T, Muller S, Moller RS, et al., De novo loss- or gain-of-function mutations in KCNA2 cause epileptic encephalopathy, Nat Genet 47 (2015) 393-399.

[246] Corbett MA, Bellows ST, Li M, Carroll R, Micallef S, Carvill GL, et al., Dominant KCNA2 mutation causes episodic ataxia and pharmacoresponsive epilepsy, Neurology 87 (2016) 1975-1984.

[247] Hundallah K, Alenizi A, AlHashem A, Tabarki B, Severe early-onset epileptic encephalopathy due to mutations in the KCNA2 gene: expansion of the genotypic and phenotypic spectrum, Eur J Paediatr Neurol 20 (2016) 657-660.

[248] Torkamani A, Bersell K, Jorge BS, Bjork RL, Jr., Friedman JR, Bloss CS, et al., De novo KCNB1 mutations in epileptic encephalopathy, Ann Neurol 76 (2014) 529-540.

[249] Saitsu H, Akita T, Tohyama J, Goldberg-Stern H, Kobayashi Y, Cohen R, et al., De novo KCNB1 mutations in infantile epilepsy inhibit repetitive neuronal firing, Sci Rep 5 (2015) 15199.

[250] Singh B, Ogiwara I, Kaneda M, Tokonami N, Mazaki E, Baba K, et al., A Kv4.2 truncation mutation in a patient with temporal lobe epilepsy, Neurobiol Dis 24 (2006) 245-253.

[251] Abidi A, Devaux JJ, Molinari F, Alcaraz G, Michon FX, Sutera-Sardo J, et al., A recurrent KCNQ2 pore mutation causing early onset epileptic encephalopathy has a moderate effect on M current but alters subcellular localization of Kv7 channels, Neurobiol Dis 80 (2015) 80-92. 
[252] Miceli F, Soldovieri MV, Ambrosino P, Barrese V, Migliore M, Cilio MR, et al., Genotype-phenotype correlations in neonatal epilepsies caused by mutations in the voltage sensor of $\mathrm{Kv} 7.2$ potassium channel subunits, Proc Natl Acad Sci USA 110 (2013) 4386-4391.

[253] Miceli F, Soldovieri MV, Ambrosino P, De Maria M, Migliore M, Migliore R, et al., Early-onset epileptic encephalopathy caused by gain-of-function mutations in the voltage sensor of Kv7.2 and Kv7.3 potassium channel subunits, J Neurosci 35 (2015) 3782-3793.

[254] Orhan G, Bock M, Schepers D, Ilina El, Reichel SN, Loffler H, et al., Dominant-negative effects of KCNQ2 mutations are associated with epileptic encephalopathy, Ann Neurol 75 (2014) 382-394.

[255] Weckhuysen S, Mandelstam S, Suls A, Audenaert D, Deconinck T, Claes LR, et al., KCNQ2 encephalopathy: emerging phenotype of a neonatal epileptic encephalopathy, Ann Neurol 71 (2012) 15-25.

[256] Hirose S, Zenri F, Akiyoshi H, Fukuma G, Iwata H, Inoue T, et al., A novel mutation of KCNQ3 (c.925T $\rightarrow C$ ) in a Japanese family with benign familial neonatal convulsions, Ann Neurol 47 (2000) 822-826.

[257] Maljevic S, Vejzovic S, Bernhard MK, Bertsche A, Weise S, Docker M, et al., Novel KCNQ3 nutation in a large family with benign familial neonatal epilepsy: a rare cause of neonatal seizures, Mol Syndromol 7 (2016) 189-196.

[258] Imbrici P, Jaffe SL, Eunson LH, Davies NP, Herd C, Robertson R, et al., Dysfunction of the brain calcium channel Cav2.1 in absence epilepsy and episodic ataxia, Brain 127 (2004) 2682-2692.

[259] Jouvenceau A, Eunson LH, Spauschus A, Ramesh V, Zuberi SM, Kullmann DM, et al., Human epilepsy associated with dysfunction of the brain P/Q-type calcium channel, Lancet 358 (2001) 801-807.

[260] Su H, Sochivko D, Becker A, Chen J, Jiang Y, Yaari Y, et al., Upregulation of a T-type $\mathrm{Ca}^{2+}$ channel $^{2}$ causes a long-lasting modification of neuronal firing mode after status epilepticus, J Neurosci 22 (2002) 3645-3655.

[261] Johannesen K, Marini C, Pfeffer S, Moller RS, Dorn T, Niturad CE, et al., Phenotypic spectrum of GABRA1: From generalized epilepsies to severe epileptic encephalopathies, Neurology 87 (2016) 1140-1151. 
[262] Maljevic S, Krampfl K, Cobilanschi J, Tilgen N, Beyer S, Weber YG, et al., A mutation in the GABA receptor $\alpha 1-$ subunit is associated with absence epilepsy, Ann Neurol 59 (2006) 983-987.

[263] Niturad CE, Lev D, Kalscheuer VM, Charzewska A, Schubert J, Lerman-Sagie T, et al., Rare GABRA3 variants are associated with epileptic seizures, encephalopathy and dysmorphic features, Brain 140 (2017) 2879-2894.

[264] Hernandez CC, Gurba KN, Hu N, Macdonald RL, The GABRA6 mutation, R46W, associated with childhood absence epilepsy, alters $\alpha 6 \beta 2 \gamma 2$ and $\alpha 6 \beta 2 \gamma$ GABAA receptor channel gating and expression, J Physiol 589 (2011) 5857-5878.

[265] Janve VS, Hernandez CC, Verdier KM, Hu N, Macdonald RL, Epileptic encephalopathy de novo GABRB mutations impair -aminobutyric acid type A receptor function, Ann Neurol 79 (2016) 806-825.

[266] Lien E, Vatevik AK, Ostern R, Haukanes BI, Houge G, A second patient with a De Novo GABRB1 mutation and epileptic encephalopathy, Ann Neurol 80 (2016) 311-312.

[267] Srivastava S, Cohen J, Pevsner J, Aradhya S, McKnight D, Butler E, et al., A novel variant in GABRB2 associated with intellectual disability and epilepsy, Am J Med Genet A 164A (2014) 2914-2921.

[268] Ishii A, Kang JQ, Schornak CC, Hernandez CC, Shen W, Watkins JC, et al., A de novo missense mutation of GABRB2 causes early myoclonic encephalopathy, J Med Genet 54 (2017) 202-211.

[269] Tanaka M, Olsen RW, Medina MT, Schwartz E, Alonso ME, Duron RM, et al., Hyperglycosylation and reduced GABA currents of mutated GABRB3 polypeptide in remitting childhood absence epilepsy, Am J Hum Genet 82 (2008) 1249-1261.

[270] Harkin LA, Bowser DN, Dibbens LM, Singh R, Phillips F, Wallace RH, et al., Truncation of the GABA receptor $\gamma 2$ subunit in a family with generalised epilepsy with febrile seizures plus, Am J Hum Genet 70 (2002) 530-536.

[271] Aridon P, Marini C, Di Resta C, Brilli E, De Fusco M, Politi F, et al., Increased sensitivity of the neuronal nicotinic receptor $\alpha 2$ subunit causes familial epilepsy with nocturnal wandering and ictal fear, Am J Hum Genet 79 (2006) 342-350. 
[272] Trivisano M, Terracciano A, Milano T, Cappelletti S, Pietrafusa N, Bertini ES, et al., Mutation of CHRNA2 in a family with benign familial infantile seizures: potential role of nicotinic acetylcholine receptor in various phenotypes of epilepsy, Epilepsia 56 (2015) e53-e57.

[273] Diaz-Otero F, Quesada M, Morales-Corraliza J, Martinez-Parra C, Gomez-Garre P, Serratosa JM, Autosomal dominant nocturnal frontal lobe epilepsy with a mutation in the CHRNB2 gene, Epilepsia 49 (2008) 516-520.

[274] Lemke JR, Geider K, Helbig KL, Heyne HO, Schutz H, Hentschel J, et al., Delineating the GRIN1 phenotypic spectrum: a distinct genetic NMDA receptor encephalopathy, Neurology 86 (2016) 2171-2178.

[275] Wu Y, Arai AC, Rumbaugh G, Srivastava AK, Turner G, Hayashi T, et al., Mutations in ionotropic AMPA receptor 3 alter channel properties and are associated with moderate cognitive impairment in humans, Proc Natl Acad Sci USA 104 (2007) 18163-18168.

[276] Martin S, Chamberlin A, Shinde DN, Hempel M, Strom TM, Schreiber A, et al., De novo variants in GRIA4 lead to intellectual disability with or without seizures and gait abnormalities, Am J Hum Genet 101 (2017) 1013-1020. 
Figure legends

Figure 1. Localisation of voltage-gated and ligand-gated ion channel subunits implicated in genetic epilepsies.

Figure 2. Overview of structural diversity in spider-venom peptides. (A) Schematic representation of the ICK motif, with $\beta$-strands shown as cyan arrows. The circled numbers indicate cysteine residues that are connected by disulfide bonds (shown as yellow lines). Note that the $\mathrm{N}$-terminal $\beta$-strand is sometimes absent. Right panel shows the NMR solution structure of $\omega$-hexatoxin-Hv1a (PDB 1AXH; [226]) with an expansion showing the ICK motif in this toxin. The $\mathrm{N}$ - and C-termini are labelled. (B) Structural variants of the ICK motif. Ribbon representations of peptide toxins are shown: huwentoxinIV (PDB 1MB6; [227]), J-ACTX-Hv1c (PDB 1DL0; [228]), ACTX-Hi:OB4219 (PDB 1KQH; [229]), hanatoxin 1 (PDB 1D1H; [230]), and $\delta$-atracotoxin-Hv1a (PDB 1VTX; [231]). The $3_{10}$ helices are shown in orange. Core disulfide bonds that form the ICK motif are shown in yellow, whereas additional non-core disulfides are shown in red.

Figure 3. Schematic illustration of vertebrate $\mathrm{Nav}_{v}$ channel $\alpha$-subunit structure and gating mechanism. (A) Eukaryotic Nav channels comprise four non-identical domains (DI-DIV) joined by cytoplasmic loops. Each domain consists of six TM segments denoted S1-S6. Within each domain, there are two functionally distinct modules. The S1-S4 segments constitute a voltage-sensing domain (VSD, depicted in blue), while the intervening P loop between S5 and S6 segments (depicted in orange) of each domain is embedded into the extracellular end of the pore to form the selectivity filter. The grey circles represent the outer (EEDD) and inner (DEKA) rings of amino acid residues of the selectivity filter. The intracellular loop between DIII and DIV forms the inactivation gate constituted by an Ile-PheMet motif. Adapted from [103]. (B) Top view of the structure of NavAb from Arcobacter butzleri obtained in a closed-pore and activated voltage-sensing domain conformation, at a resolution of $2.7 \AA$ (PDB 3RVY). The central pore is shown in orange and the voltage-sensing domain is shown in blue. Adapted from [232]. (C) Side views of the structure of NavPaS from the American cockroach Periplaneta 
americana, at a resolution of $3.8 \AA$ (PDB 5XOM). The structure was captured in a closed conformation with the four VSDs adopting a range of semi-activated states. Each domain is coloured with green for the N-terminal domain, orange for the DIII-IV linker, and purple for the C-terminal domain. Adapted from [233]. (D) Nav channels exist in at least three functional states (open, closed and inactivated) depending on the membrane potential during AP evolution. (E) Classic Nav channel current profile recorded from human embryonic kidney (HEK)293 cells using the whole-cell patch-clamp electrophysiology technique. Depolarisation of the membrane potential from $-80 \mathrm{mV}$ to $0 \mathrm{mV}$ leads to opening of the channel and rapid influx of sodium ions through channel pore. Within a few milliseconds, the inactivation gate occludes the pore, the channel inactivates, and no current flows. Upon membrane repolarisation back to $-80 \mathrm{mV}$, the channel recovers from inactivation and can be activated again.

Figure 4. The role of Nav1.1 in the pathogenesis of Dravet syndrome. (A) Nav1.1 channels are pivotal for AP generation in GABAergic inhibitory interneurons (blue). AP generation by Nav1.1 channels at the axon initial segment causes membrane depolarisation that activates Cav channels, resulting in influx of $\mathrm{Ca}^{2+}$ ions. This triggers exocytotic release of GABA into the synaptic cleft. When GABA binds to $\mathrm{GABA}_{\mathrm{A}}$ receptors on the postsynaptic membrane of excitatory neurons (purple), it causes rapid influx of $\mathrm{Cl}^{-}$ions leading to a hyperpolarised membrane potential. This makes it more difficult to initiate an AP in the postsynaptic cells. Non-selective Nav channel blockers such as carbamazepine, lamotrigine and phenytoin, are contraindicated in DS as they would be expected to decrease depolarisationinduced $\mathrm{Ca}^{2+}$ ion influx and vesicular release of GABA, leading to enhanced hyperexcitability of the postsynaptic excitatory neurons. In contrast, compounds that enhance GABAergic neurotransmission, such as stiripentol, clobazam and valproate, are therapeutically beneficial in DS. (B) The neuronal networks (depicted as orange/red circuits) located within different brain regions are comprised of distinct cell types. Under normal conditions, the activity of excitatory neurons is regulated by inhibitory neurons (top row). In DS, LOF mutations in Nav1.1 lead to reduced excitability of inhibitory neurons and decreased GABA release. The excitatory neurons thus become disinhibited, resulting in seizures 
due to uncontrolled hyperexcitability (bottom row). (C) Alignment of $\mathrm{Hm} 1 \mathrm{a}$ and $\mathrm{Hm} 1 \mathrm{~b}$ peptides [111]. Cysteine residues characteristic of ICK peptides are shown in bold. Disulfide-bond connectivities are illustrated above the sequences. Asterisks denote C-terminal amidation. (D) NMR solution structures of Hm1a (PDB 2N6O; [21]) and Hm1b (PDB 6V6T). The N- and C-termini are labelled. The antiparallel $\beta$ strands are coloured blue, whereas the $\alpha$-helix is coloured red. The three disulfide bonds are shown in yellow. (E) Representative currents of human Nav1.1 activated by depolarisation at $0 \mathrm{mV}$ in the presence of vehicle (black) or $300 \mathrm{nM} \mathrm{Hm1a} \mathrm{(red,} \mathrm{left)} \mathrm{or} 300 \mathrm{nM} \mathrm{Hm1b}$ (red, right). In the presence of $\mathrm{Hm} 1 \mathrm{a}$ and $\mathrm{Hm} 1 \mathrm{~b}$, there are sustained Nav1.1 currents at the end of a depolarising pulse.

Figure 5. Schematic illustration of ligand-gated ion channel superfamilies. (A-C) Cartoon depiction showing the quaternary and tertiary structures of LGIC superfamilies. (A) The Cys-loop receptors are pentameric LGICs with five subunits arranged around a central pore. Each subunit contains a large extracellular domain, four TM domains, two short M1-M2 and M2-M3 loops, a large intracellular M3M4 loop and a short C-terminal region. The native ligand binds at the interface between two subunits in the extracellular domain. (B) The ionotropic glutamate receptors are tetrameric ligand-gated ion channels with a dimer of dimers that form four subunits surrounding the ion channel. Each subunit contains an extracellular domain, a ligand-binding domain, three TM domains (M1, M3 and M4), and an M2 re-entrant loop. The agonist binding site is within a subunit in the extracellular domain. (C) P2X receptors are trimeric ligand-gated ion channels with three subunits arranged around a central ion channel pore. Each subunit contains two intracellular termini, two TM domains and a large extracellular region connecting the M1 and M2 that contains the ATP-binding site between adjacent subunits. (D-F) High resolution structures of the (D) $\alpha 1 \beta 3 \gamma 2 \mathrm{GABA}_{\mathrm{A}}$ receptor (PDB 6153; [234]), (E) AMPA receptor (PDB 5WEM; [235]), and (F) P2X 7 receptor (PDB 6U9V; [236]). 
Table 1: Overview of epilepsy-related ion channels.

\begin{tabular}{|c|c|c|c|c|c|c|}
\hline Channel & Gene & Subtype & $\begin{array}{l}\text { Epilepsy } \\
\text { syndrome }\end{array}$ & $\begin{array}{l}\text { Molecular } \\
\text { Phenotype }\end{array}$ & Epileptogenic mechanism & Reference \\
\hline \multirow[t]{4}{*}{$\mathrm{Nav}$} & SCN1A & $\begin{array}{l}\text { Nav1.1 } \\
\alpha \text {-subunit }\end{array}$ & DS; GEFS+; IS & LOF variants & $\begin{array}{l}\text { Decreased excitability of fast-spiking } \\
\text { GABAergic inhibitory interneurons }\end{array}$ & {$[237-239]$} \\
\hline & SCN1B & $\begin{array}{l}\mathrm{Nav} \\
\beta 1 \text {-subunit }\end{array}$ & DS; GEFS+; TLE & LOF variants & $\begin{array}{l}\text { Increased excitability of glutamatergic } \\
\text { pyramidal neurons }\end{array}$ & [240-242] \\
\hline & $S C N 2 A$ & $\begin{array}{l}\text { Nav1.2 } \\
\alpha \text {-subunit }\end{array}$ & BFNIE; DS; EE & LOF or GOF variants & $\begin{array}{l}\text { Increased excitability of glutamatergic } \\
\text { pyramidal neurons }\end{array}$ & $\begin{array}{c}{[71,112} \\
243]\end{array}$ \\
\hline & SCN8A & $\begin{array}{l}\text { Nav1.6 } \\
\alpha \text {-subunit }\end{array}$ & BFIE & GOF variants & $\begin{array}{l}\text { Increased excitability of glutamatergic } \\
\text { pyramidal neurons; reduced } \\
\text { inhibitory neuron function }\end{array}$ & [117] \\
\hline \multirow[t]{8}{*}{$\mathrm{K}_{\mathrm{v}}$} & KCNA1 & $\begin{array}{l}K_{v} 1.1 \\
\alpha \text {-subunit }\end{array}$ & EA1 & LOF variants & Changes in neurotransmitter release? & {$[135,244]$} \\
\hline & KCNA2 & $\begin{array}{l}\mathrm{K}_{\mathrm{v}} 1.2 \\
\alpha \text {-subunit }\end{array}$ & $\mathrm{EE}, \mathrm{EA}$ & LOF or GOF variants & Changes in neurotransmitter release? & [245-247] \\
\hline & KCNB1 & $\begin{array}{l}K_{v} 2.1 \\
\alpha \text {-subunit }\end{array}$ & $\mathrm{EE}, \mathrm{IE}$ & Missense variants & Increased neuronal excitability? & {$[248,249]$} \\
\hline & KCNC1 & $\begin{array}{l}\text { Kv3.1 } \\
\alpha \text {-subunit }\end{array}$ & PME & LOF variants & $\begin{array}{l}\text { Decreased excitability of fast-spiking } \\
\text { GABAergic interneurons }\end{array}$ & [136] \\
\hline & KCND2 & $\begin{array}{l}\mathrm{K}_{\mathrm{v}} 4.2 \\
\alpha \text {-subunit }\end{array}$ & TLE & $\begin{array}{l}\text { Partial LOF } \\
\text { truncated variants }\end{array}$ & $\begin{array}{l}\text { Partial loss-of-function truncation } \\
\text { mutation leads to aberrant neuronal } \\
\text { excitability }\end{array}$ & [250] \\
\hline & KCNQ2 & $\begin{array}{l}\mathrm{K}_{\mathrm{v}} 7.2 \\
\alpha \text {-subunit }\end{array}$ & $\begin{array}{l}\text { BFNE, VRE, } \\
\text { NOEE, DRPE }\end{array}$ & LOF variants & Reduction in the M-current & $\begin{array}{l}{[137,138,} \\
251-255]\end{array}$ \\
\hline & KCNQ3 & $\begin{array}{l}\text { Kv7.3 } \\
\alpha \text {-subunit }\end{array}$ & BFNE & LOF variants & Reduction in the M-current & $\begin{array}{l}{[253,256,} \\
257]\end{array}$ \\
\hline & KCNH1 & $\begin{array}{l}\mathrm{K}_{\vee} 10.1 \\
\alpha \text {-subunit }\end{array}$ & TBS; ZLS & GOF variants & Increased neuronal excitability & {$[43,139]$} \\
\hline \multirow[t]{3}{*}{$\mathrm{Cav}$} & CACNA1A & $\begin{array}{l}\text { Cav2.1 } \\
\text { a1-subunit }\end{array}$ & $\mathrm{EE} ; \mathrm{IGE}$ & LOF variants & Changes in neurotransmitter release & $\begin{array}{l}{[155,258,} \\
259]\end{array}$ \\
\hline & CACNA1H & $\begin{array}{l}\text { Cav3.2 } \\
\text { a1-subunit }\end{array}$ & JME; TLE; IGE & GOF variants & $\begin{array}{l}\text { Increased neuronal excitability } \\
\text { promoting EPSPs? }\end{array}$ & $\begin{array}{l}{[159,161,} \\
260]\end{array}$ \\
\hline & CACNB4 & $\begin{array}{l}\text { Cav2.1 } \\
\text { B4-subunit }\end{array}$ & JME & Unknown & Unknown & [158] \\
\hline \multirow[t]{9}{*}{$\mathrm{GABA}_{\mathrm{A}}$} & GABRA1 & $\begin{array}{l}\mathrm{GABA}_{A} \\
\alpha 1 \text {-subunit }\end{array}$ & $\begin{array}{l}\text { CAE; EE; GEFS+; } \\
\text { JME }\end{array}$ & $\begin{array}{l}\text { Impaired GABAergic } \\
\text { inhibition function } \\
\text { or expression }\end{array}$ & $\begin{array}{l}\text { Expected reduction in GABAergic } \\
\text { inhibition }\end{array}$ & $\begin{array}{c}{[183,261,} \\
262]\end{array}$ \\
\hline & GABRA2 & $\begin{array}{l}\mathrm{GABA}_{A} \\
\alpha 2 \text {-subunit }\end{array}$ & $\mathrm{EE}$ & $\begin{array}{l}\text { Impaired GABAergic } \\
\text { function }\end{array}$ & $\begin{array}{l}\text { Expected reduction in GABAergic } \\
\text { inhibition }\end{array}$ & [198] \\
\hline & GABRA3 & $\begin{array}{l}\mathrm{GABA}_{A} \\
\text { a3-subunit }\end{array}$ & CAE; EE; IS & $\begin{array}{l}\text { Impaired GABAergic } \\
\text { function }\end{array}$ & $\begin{array}{l}\text { Expected reduction in GABAergic } \\
\text { inhibition }\end{array}$ & [263] \\
\hline & GABRA5 & $\begin{array}{l}\mathrm{GABA}_{\mathrm{A}} \\
\alpha 5 \text {-subunit }\end{array}$ & $\mathrm{EE}$ & $\begin{array}{l}\text { Increased GABAAR } \\
\text { desensitisation }\end{array}$ & $\begin{array}{l}\text { Expected reduction in GABAergic } \\
\text { inhibition }\end{array}$ & [198] \\
\hline & GABRA6 & $\begin{array}{l}\mathrm{GABA}_{\mathrm{A}} \\
\alpha 6 \text {-subunit }\end{array}$ & CAE & $\begin{array}{l}\text { Impaired GABAergic } \\
\text { function }\end{array}$ & $\begin{array}{l}\text { Expected reduction in GABAergic } \\
\text { inhibition }\end{array}$ & [264] \\
\hline & $G A B R B 1$ & $\begin{array}{l}\mathrm{GABA}_{A} \\
\beta 1 \text {-subunit }\end{array}$ & LGS & $\begin{array}{l}\text { Impaired GABAergic } \\
\text { function }\end{array}$ & $\begin{array}{l}\text { Expected reduction in GABAergic } \\
\text { inhibition }\end{array}$ & {$[265,266]$} \\
\hline & GABRB2 & $\begin{array}{l}\mathrm{GABA}_{A} \\
\beta 2 \text {-subunit }\end{array}$ & GEFS+ & Missense variant & $\begin{array}{l}\text { Expected reduction in GABAergic } \\
\text { inhibition }\end{array}$ & [267] \\
\hline & GABRB3 & $\begin{array}{l}\mathrm{GABA}_{\mathrm{A}} \\
\beta 3 \text {-subunit }\end{array}$ & CAE; EE; IS; LGS & $\begin{array}{l}\text { Impaired GABAergic } \\
\text { inhibition function }\end{array}$ & $\begin{array}{l}\text { Expected reduction in GABAergic } \\
\text { inhibition }\end{array}$ & $\begin{array}{l}{[184,265,} \\
268,269]\end{array}$ \\
\hline & GABRG2 & $\begin{array}{l}\mathrm{GABA}_{A} \\
\gamma 2 \text {-subunit }\end{array}$ & DS; EE; GEFS+ & $\begin{array}{l}\text { Impaired GABAergic } \\
\text { inhibition function } \\
\text { or expression }\end{array}$ & $\begin{array}{l}\text { Expected reduction in GABAergic } \\
\text { inhibition }\end{array}$ & {$[54,270]$} \\
\hline \multirow[t]{2}{*}{$\mathrm{nAChR}$} & CHRNA2 & $\begin{array}{l}\text { nAChR } \\
\alpha 2 \text {-subunit }\end{array}$ & ADNFLE; BFIE & GOF variants & $\begin{array}{l}\text { Decreased excitability of fast-spiking } \\
\text { GABAergic interneurons }\end{array}$ & {$[271,272]$} \\
\hline & CHRNA4 & $\mathrm{nAChR}$ & ADNFLE & GOF variants & Changes in neurotransmitter release? & [42] \\
\hline
\end{tabular}




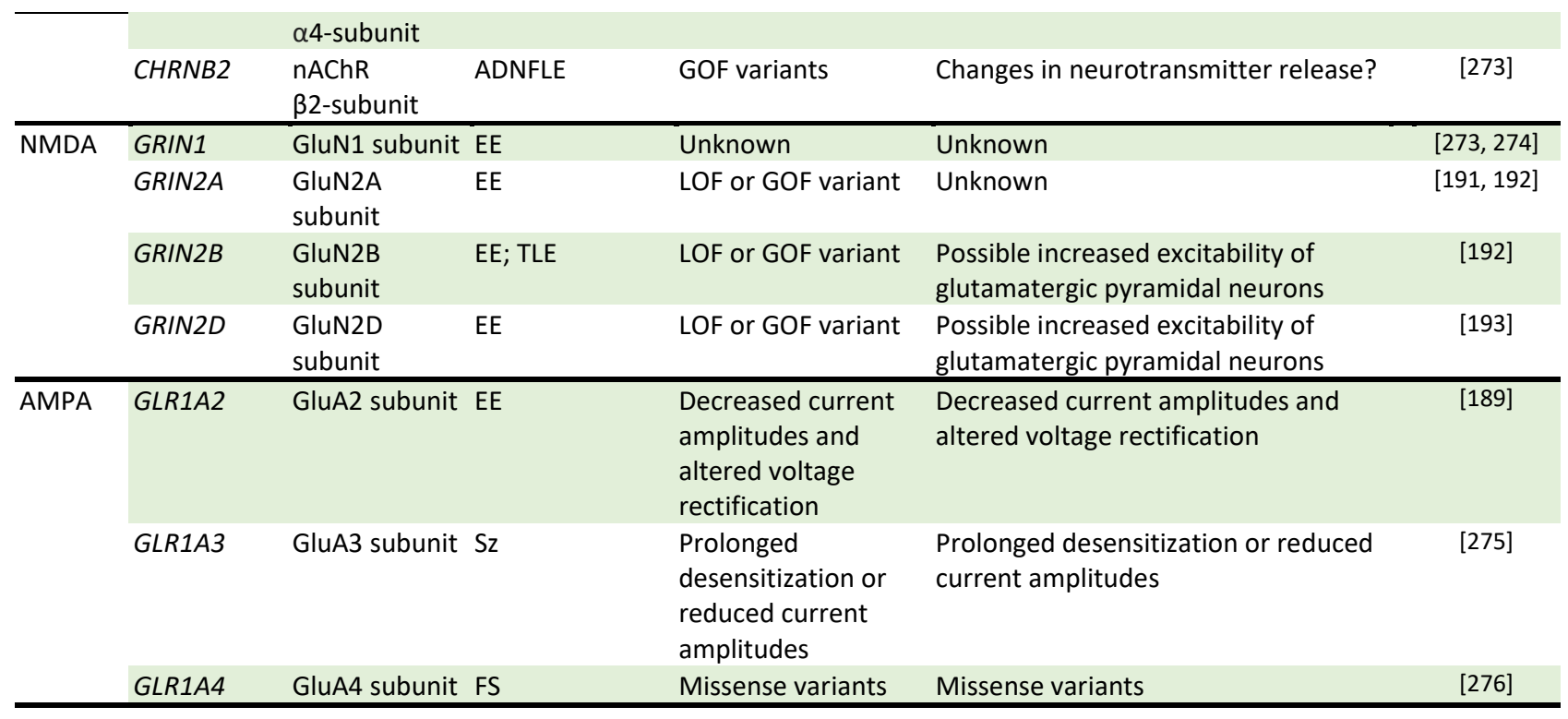


Table 2: Commonly used drugs for the treatment of epilepsy. Approval year is the year in which the drug was first approved or marketed in the USA or Europe. Abbreviation: AMPA, $\alpha$-amino-3-hydroxy5-methyl-4-isoxazolepropionic acid subtype of glutamate receptor.

\begin{tabular}{|c|c|c|}
\hline Drug & $\begin{array}{l}\text { Approval } \\
\text { year }\end{array}$ & Presumed mechanism(s) of action \\
\hline \multicolumn{3}{|l|}{ First generation } \\
\hline Potassium bromide & 1857 & Thought to hyperpolarize cells by traversing $G A B A_{A}$ receptors \\
\hline Phenobarbital & 1912 & Potentiation of $\mathrm{GABA}_{\mathrm{A}}$ receptors \\
\hline Primidone & 1952 & $\begin{array}{l}\text { Potentiation of } \mathrm{GABA}_{\mathrm{A}} \text { receptors; metabolised to Phenobarbital } \\
\text { in vivo }\end{array}$ \\
\hline Phenytoin & 1953 & Nav channel inactivation \\
\hline Ethosuximide & 1960 & T-type Cav channel blockade \\
\hline Diazepam & 1963 & Potentiation of $\mathrm{GABA}_{\mathrm{A}}$ receptors \\
\hline Carbamazepine & 1964 & T-type Cav channel blockade; Nav channel inactivation \\
\hline Valproate & 1967 & $\begin{array}{l}\text { Increased GABA concentrations; Potentiation of GABAA } \\
\text { receptors; Nav channel blockade }\end{array}$ \\
\hline Clonazepam & 1968 & Potentiation of $\mathrm{GABA}_{\mathrm{A}}$ receptors \\
\hline \multicolumn{3}{|l|}{ Second generation } \\
\hline Lamotrigine & 1990 & Glutamate receptor (AMPA) antagonist; Nav channel blockade \\
\hline Oxcarbazepine & 1990 & Nav channel inactivation \\
\hline Gabapentin & 1993 & Cav channel ( $\alpha 2 \delta$ subunit) blockade \\
\hline Topiramate & 1995 & $\begin{array}{l}\text { Potentiation of GABAA receptors; glutamate receptor (kainate) } \\
\text { antagonist; Nav channel blockade }\end{array}$ \\
\hline Tiagabine & 1997 & Inhibits GABA-transporter 1 \\
\hline Levetiracetam & 1999 & $\begin{array}{l}\text { Binds to synaptic vesicle glycoprotein } 2 \mathrm{~A} \text {; inhibits presynaptic Cav } \\
\text { channels }\end{array}$ \\
\hline Zonisamide & 2000 & Nav channel blockade; T-type Cav channel blockade \\
\hline Pregabalin & 2004 & Cav channel ( $\alpha 2 \delta$ subunit) blockade \\
\hline Rufinamide & 2004 & Nav channel inactivation \\
\hline \multicolumn{3}{|l|}{ Third generation } \\
\hline Lacosamide & 2008 & Enhance Nav channel slow inactivation \\
\hline Vigabatrin & 2009 & $\begin{array}{l}\text { Increases GABA concentration by inhibiting the mitochondrial } \\
\text { enzyme GABA transaminase }\end{array}$ \\
\hline Clobazam & 2011 & Potentiation of $\mathrm{GABA}_{\mathrm{A}}$ receptors \\
\hline Ezogabine & 2011 & Enhances activation of Kv7 channels \\
\hline Perampanel & 2012 & Glutamate receptor (AMPA) antagonist \\
\hline Eslicarbazepine acetate & 2013 & Nav channel blockade \\
\hline Cannabidiol & 2018 & $\begin{array}{l}\text { Potentiation of GABA } \text { receptors; Reduce metabolism of } \\
\text { clobazam; GPR55 antagonist }\end{array}$ \\
\hline Stiripentol & 2018 & $\begin{array}{l}\text { Potentiation of GABAA receptors; Reduce metabolism of } \\
\text { clobazam }\end{array}$ \\
\hline
\end{tabular}


Figure 1

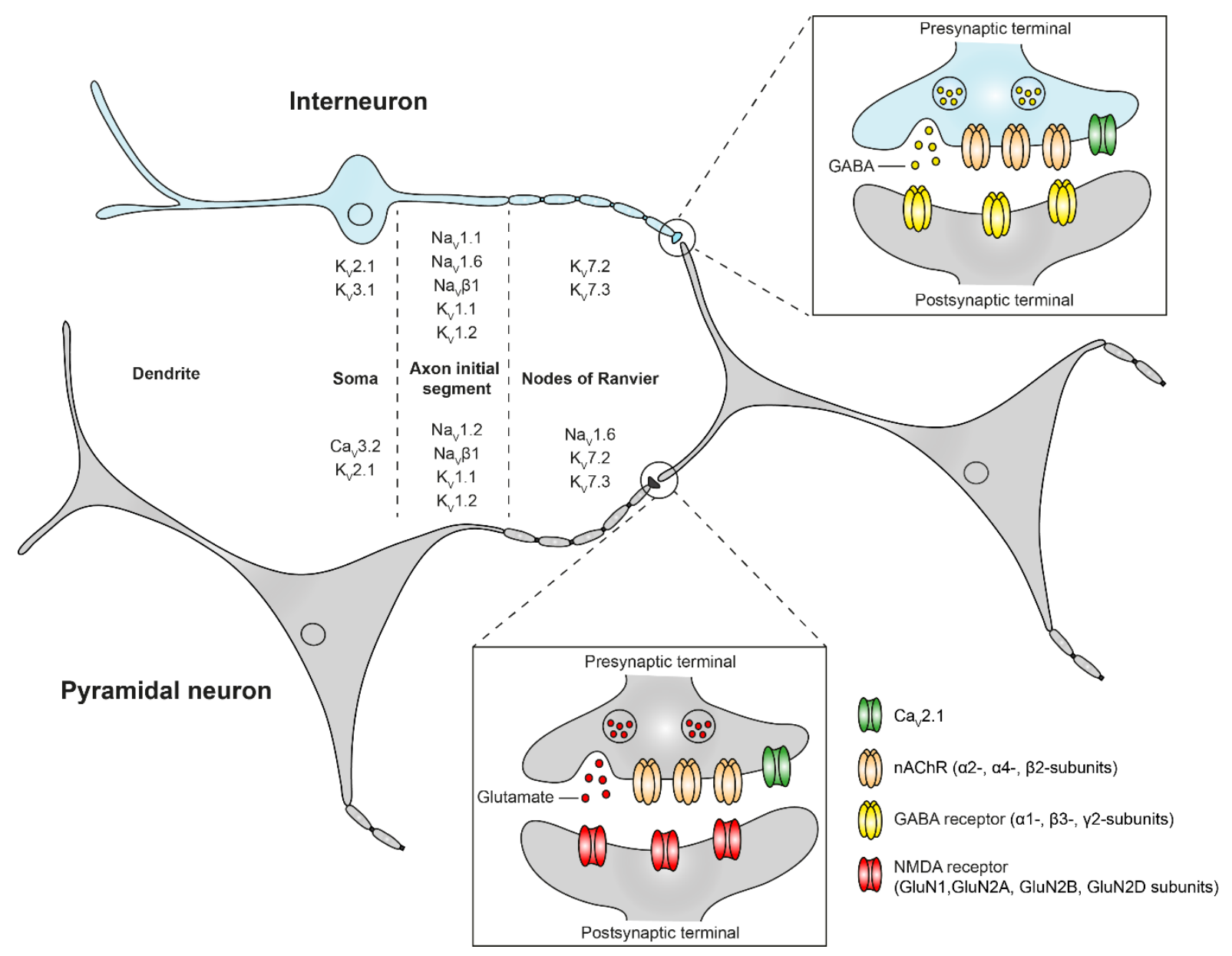


Figure 2

A
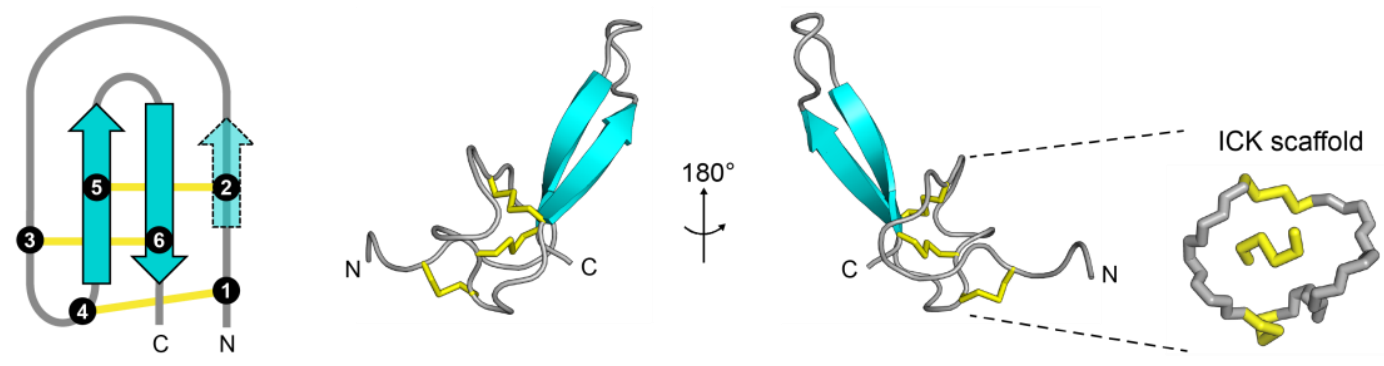

B

Huwentoxin-IV ( $\beta \beta)$

J-ACTX-Hv1c $(\beta \beta)$

ACTX-Hi:OB4219 ( $\beta \beta \beta)$

Hanatoxin $1\left(3_{10} \beta \beta\right) \quad \bar{\delta}$-atracotoxin-Hv1a $\left(\beta \beta \beta 3_{10}\right)$
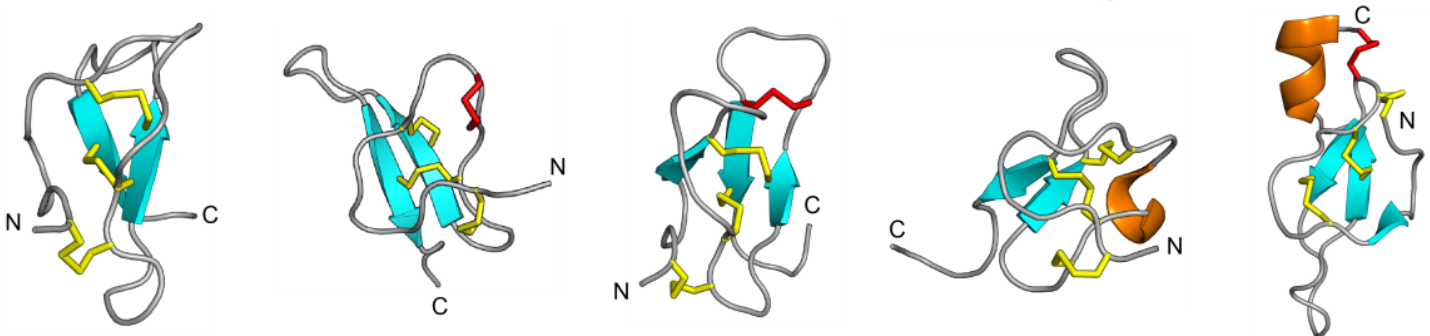
Figure 3

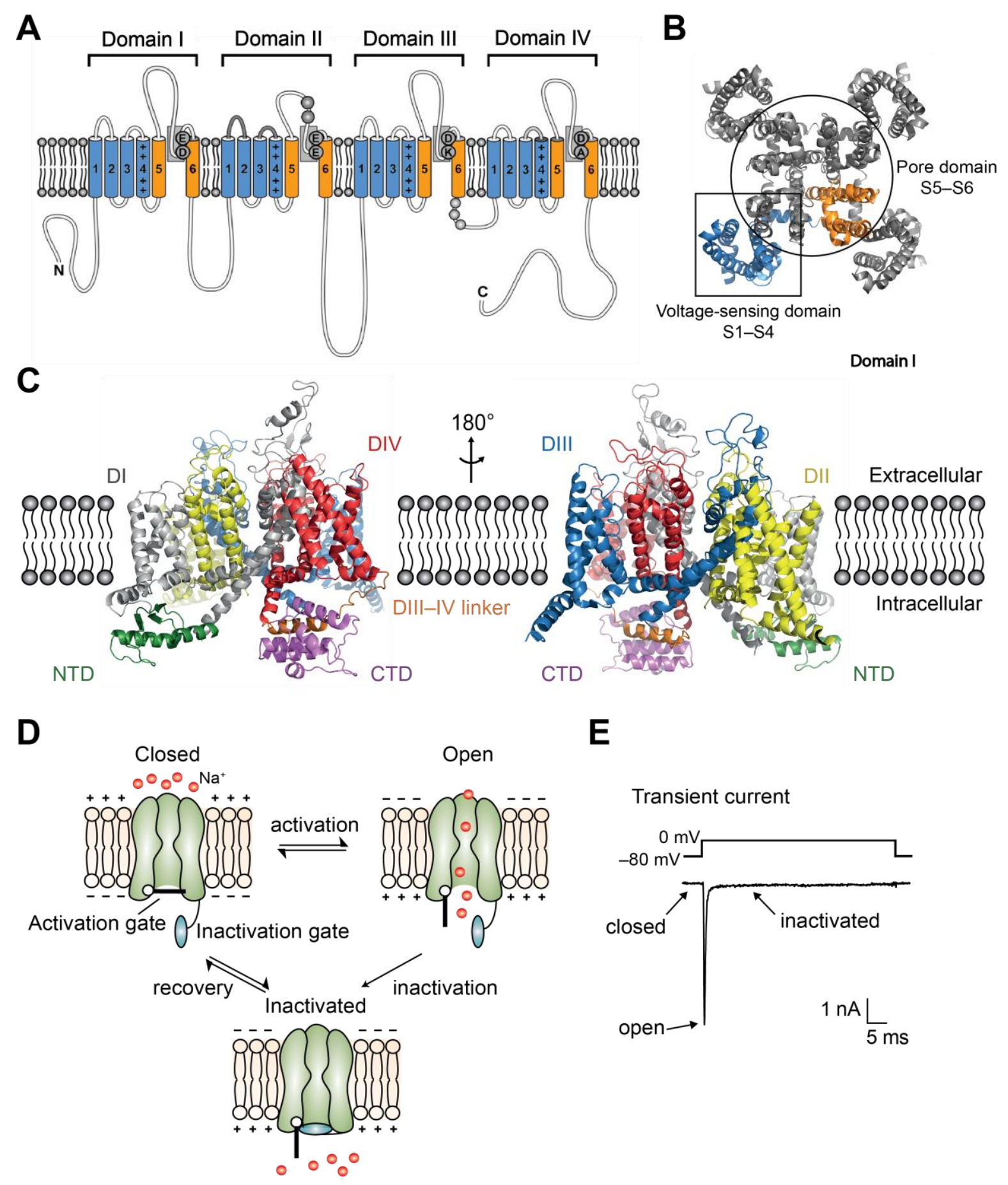


Figure 4

A

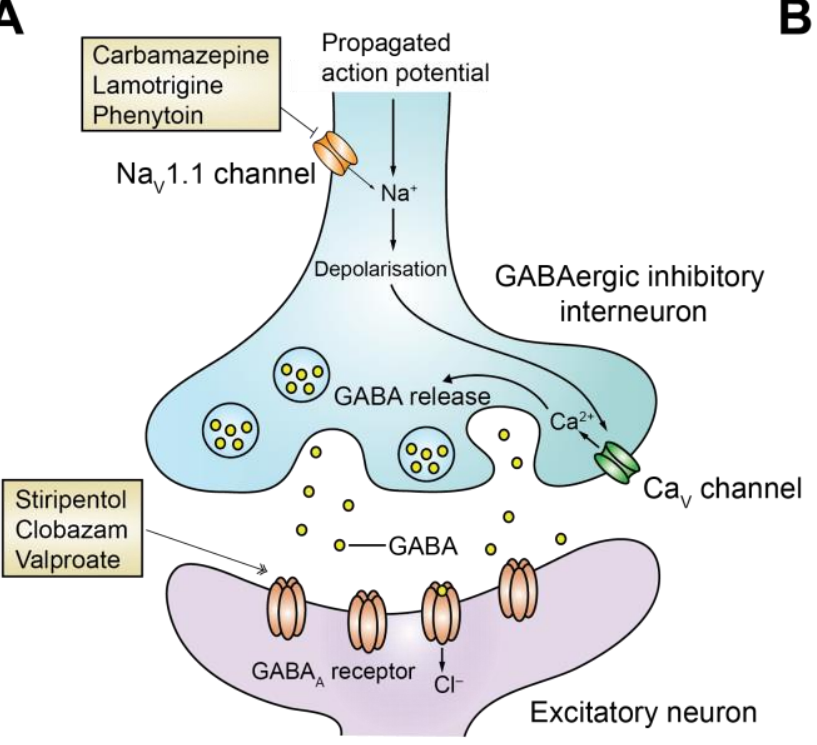

B

Inhibition

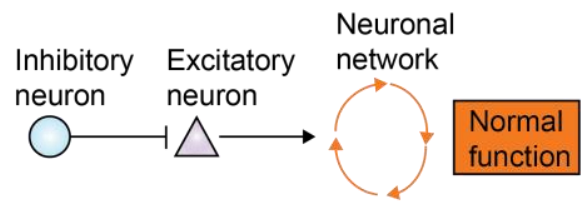

Disinhibition

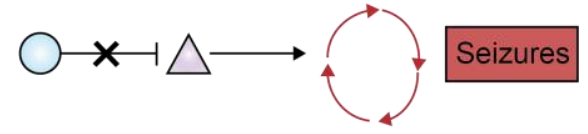

C

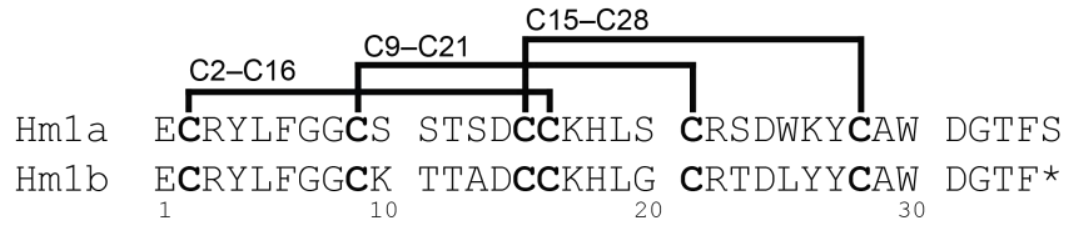

D

Hm1a

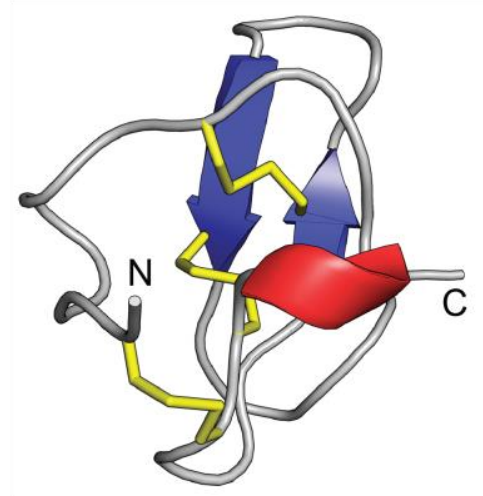

E

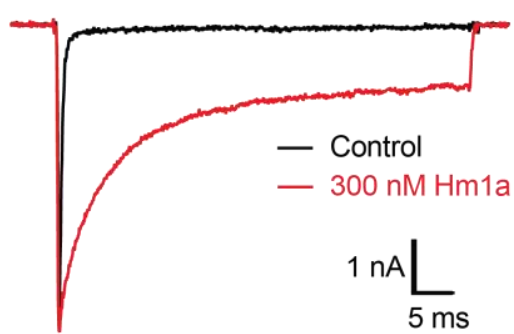

$\mathrm{Hm} 1 \mathrm{~b}$
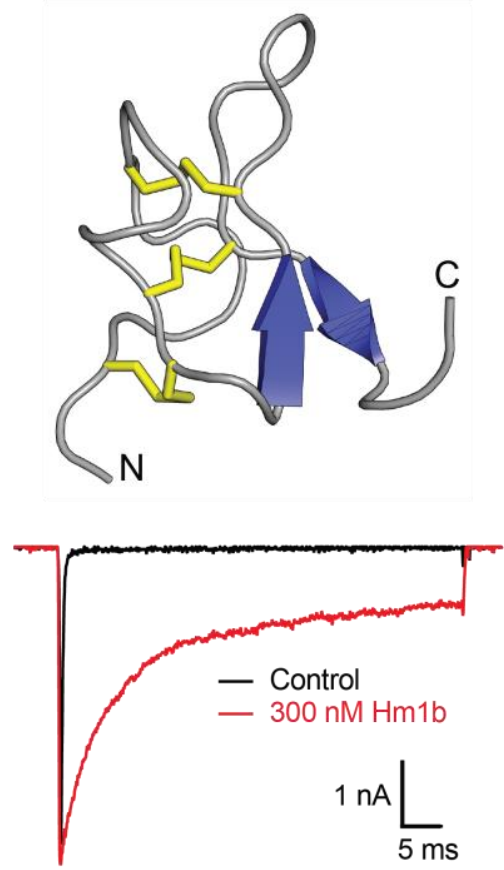
Figure 5
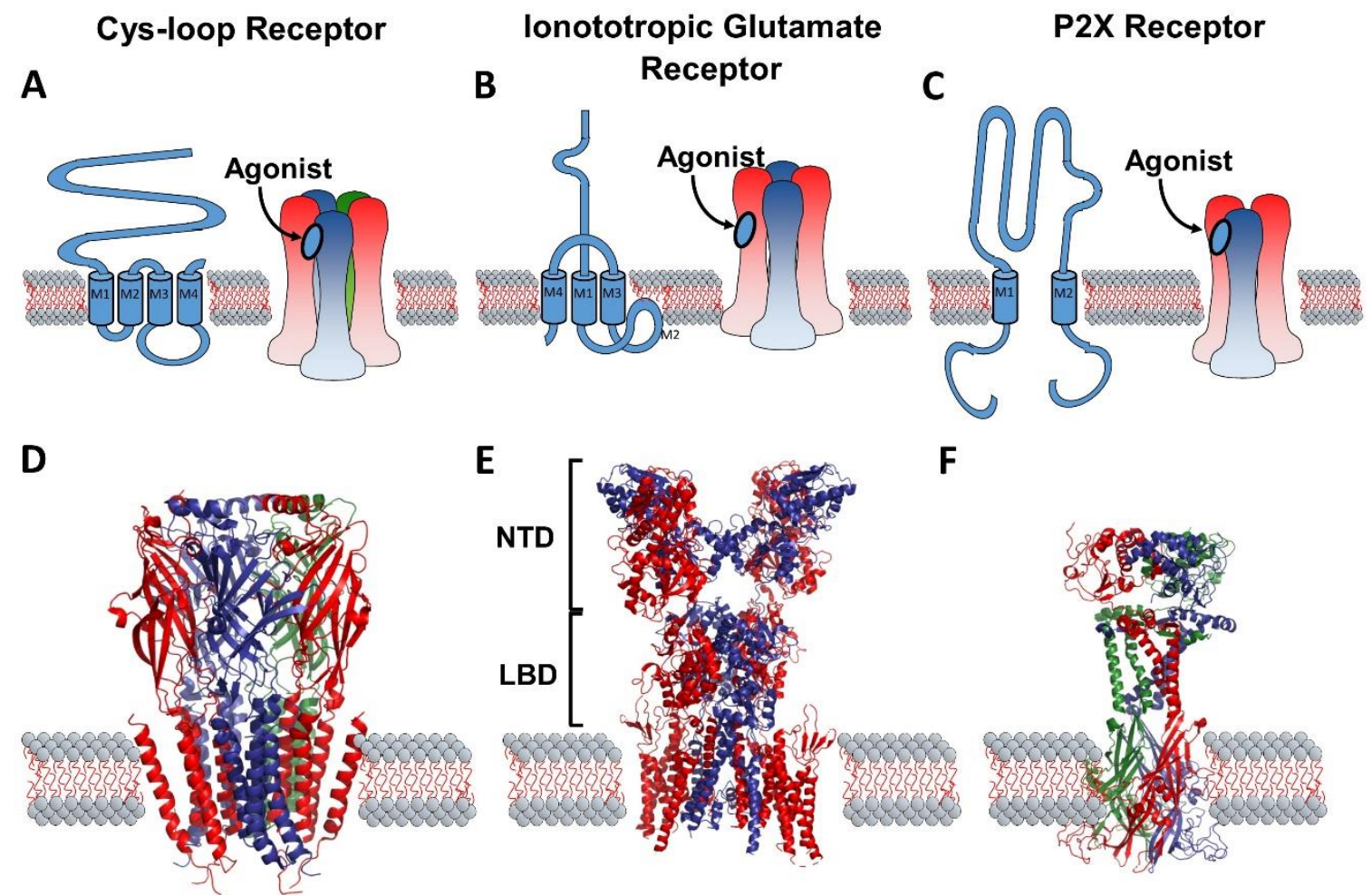

GABA $_{A}$ Receptor

AMPA Receptor

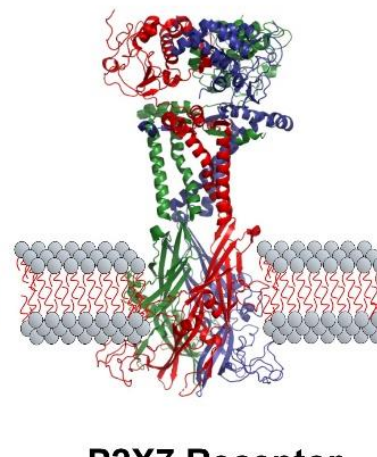

